\title{
Technology Adoption, Capital Deepening, and International Productivity Differences*
}

\author{
Job Market Paper. Click here for latest version. \\ Chaoran Chen \\ University of Toronto
}

November 22, 2016

Cross-country differences in capital intensity are larger in the agricultural sector than in the non-agricultural sector, indicating that rich and poor countries differ in agricultural technology adoption. I build a two-sector general equilibrium model featuring technology adoption in agriculture. As the economy develops, farmers gradually adopt a modern capital-intensive technology to replace the traditional labour-intensive technology, as is observed in the U.S. historical data. Using this model, I find that the technology adoption channel is key to accounting for low agricultural capital intensity and labour productivity in poor countries. In the model, measured aggregate factors - land endowment, economy-wide productivity, and barriers to investment - can explain 1.56-fold more in rich-poor agricultural productivity differences compared to a model without technology adoption. I further show that land market frictions in agriculture impede technology adoption and magnify productivity differences.

Keywords: Technology Adoption, Capital Intensity, Agricultural Productivity, Misallocation.

JEL classification: E13, O41, Q12, Q16.

${ }^{*}$ I thank Diego Restuccia for his encouragement and supervision. I also benefit from discussions with Stephen Ayerst, Margarida Duarte, Peter Morrow, Michael Peters, Michael Sposi, Joseph Steinberg, and Xiaodong Zhu, as well as various conference and seminar participants at Canadian Economics Association at Ottawa, EconCon at Princeton, Midwest Macro at Purdue, Shanghai University of Finance and Economics, and University of Toronto. All errors are my own. Contact: Department of Economics, University of Toronto, 150 St. George Street, Toronto, Ontario, Canada, M5S 3G7. Email: chaoran.chen@mail.utoronto.ca. 


\section{Introduction}

Cross-country labour productivity differences are larger in the agricultural sector than in the non-agricultural sector. Moreover, poor countries allocate a larger percentage of employment to their agricultural sector due to low agricultural productivity and the need to meet the subsistence requirement for the agricultural good (Caselli, 2005; Restuccia et al., 2008). In this paper, I study the cross-country agricultural productivity differences through the lens of technology adoption, where rich countries mechanize their agricultural production using modern capital-intensive technology, while poor countries use less productive traditional technology with low capital intensity.

The difference in agricultural technology adoption is motivated by a new stylized fact that has not yet been explored in the literature: agricultural production in poor countries is far less capital intensive than in rich countries. I construct a new cross-country dataset on sectoral capital intensity, which can be measured by either the capital-output ratio or the capital-labour ratio. I find that capital intensity is generally lower in poor countries, and that the differences are particularly large in the agricultural sector. This indicates that rich and poor countries use different agricultural technology embedded in the capital stock, which is also confirmed by observed cross-country differences in modern machinery inputs in agriculture, such as tractors and combine harvesters.

To study changes in agricultural technology over time, I explore historical data for the United States on capital intensity and agricultural technology, covering the twentieth century. I find that although the capital-output ratio remained relatively constant in the nonagricultural sector, it increased over time in the agricultural sector. This century also saw massive mechanization of the U.S. agricultural production process, especially in the postwar period, when farmers substituted labour with tractors, harvesters, and other major 
machines. ${ }^{1}$ Motivated by these pieces of evidence, I address two research questions in this paper: why poor countries have not mechanized their agricultural production, and how differences in agricultural technology contribute to international differences in agricultural capital intensity and labour productivity.

I model the observed mechanization as a process of technology adoption in agriculture. I build a general equilibrium model with an agricultural sector and a non-agricultural sector, allowing for technology adoption in agriculture. Farmers choose from two technologies: a traditional labour-intensive technology with a lower capital share and a lower total factor productivity (TFP), and a modern capital-intensive technology with a higher capital share and a higher TFP. As the economy develops, capital becomes cheaper relative to labour, and as a result, farming with modern technology becomes more profitable and the traditional technology is gradually replaced. Along with this process, agricultural labour productivity increases for two reasons. First, capital intensity increases in agriculture, which increases labour productivity. This is the capital deepening effect. Second and more importantly, there is an increase in agricultural sectoral TFP that is embedded in the capital deepening process, since the modern technology has a higher TFP than the traditional technology. As a result, the model is consistent with the data that, in the U.S., we observe rapid agricultural labour productivity growth over the twentieth century, together with an increased capital-output ratio in agriculture. It follows that, the observed cross-country variation in agricultural capital intensity can reflect underlying differences in technology adoption and the associated differences in sectoral TFP. The international differences in both capital intensity and sectoral TFP contribute to agricultural labour productivity differences.

To discipline the analysis, I calibrate this model to U.S. historical data covering the entirety of the twentieth century (1900-2000). The model successfully replicates the time series of agricultural employment share, labour productivity, capital intensity, and, in par-

\footnotetext{
${ }^{1}$ See Sunding and Zilberman (2001) for an excellent discussion on technology adoption in agriculture.
} 
ticular, the technology adoption curve as seen in the historical U.S. data. Then I use this model reflecting mechanization in the U.S., which is my benchmark, to study the lack of mechanization in the poor countries. This calibrated model allows me to identify whether the lack of mechanization in poor countries is due to their different stages of development, or due to exogenous frictions that impede technology adoption. I first focus on aggregate factors by measuring economy-wide TFP and barrier to investment. These aggregate factors affect both the agricultural and non-agricultural sectors. I estimate these aggregate factors using moments from the non-agricultural sector since I treat it as exogenous. I also control for land and labour endowments. I then vary the model parameters to match the moments of the non-agricultural sector of the poorest countries. I find that these aggregate factors can explain two thirds of the observed differences between the U.S. and the poorest countries in terms of agricultural capital intensity and labour productivity. Furthermore, I find that technology adoption is crucial for the model to match the data. Without a technology adoption choice, the model would predict higher agricultural capital-output ratio for poor countries than for rich countries, which is opposite to what we observe in the data.

To explain the remaining portion of observed differences, I explore the role of land misallocation as a potential candidate. Recent literature emphasizes that land market misallocation is especially severe in the agricultural sector in poor countries. ${ }^{2}$ I extend my model to include untitled land, where farmers are allocated exogenous amounts of land and land rentals among farmers are prohibited due to a lack of proper ownership. This form of land misallocation is common in less developed countries with poor institutions (Chen, 2016). I find that land misallocation further reduces the capital intensity and agricultural productivity. The model is able to explain almost all the observed differences between the U.S. and poor countries with respect to capital intensity and $72 \%$ of the agricultural productivity differ-

\footnotetext{
${ }^{2}$ See, for example, Adamopoulos and Restuccia (2014), Adamopoulos and Restuccia (2015), and Chen (2016), among others.
} 
ences with untitled land and aggregate factors. Intuitively, farming with modern technology is only profitable if farm size is large enough for farmers to use machines to replace human labour. If farmers cannot buy or rent additional land to expand their farm size, then they have little incentive to adopt the modern technology. Other forms of land misallocation, such as imposing ceilings on farm size, as described in Adamopoulos and Restuccia (2015), have similar impact on technology adoption and agricultural productivity.

My paper is related to the macroeconomic literature on agricultural productivity differences across countries. ${ }^{3}$ My paper differs from existing literature in that I introduce technology adoption in agriculture to capture the phenomenon of mechanization. A closely related paper is Caunedo and Keller (2016), which finds that the quality of agricultural capital differs across countries, and this fact accounts for $40 \%$ of agricultural productivity differences among rich and middle-income countries. By focusing on agricultural capital intensity differences across countries, my paper complements their findings on capital quality differences. ${ }^{4}$ Caunedo and Keller (2016) further quantify the impact of capital quality through a development accounting exercise. On the contrary, I employ a technology adoption mechanism, which endogenously generates differences in agricultural capital intensity and labour productivity jointly in the equilibrium. My model also matches the U.S. historical data on structural transformation, capital intensity, and technology adoption.

My paper is also related to the literature studying long-run economic growth, in particular, the transition to the modern balanced growth path. ${ }^{5}$ Two closely related papers are Gollin et al. (2007) and Yang and Zhu (2013). They both model the choice between a

\footnotetext{
${ }^{3}$ See, for example, Gollin et al. (2002), Gollin et al. (2004), Gollin et al. (2007), Restuccia et al. (2008), Adamopoulos (2011), Lagakos and Waugh (2013), Gollin and Rogerson (2014), Donovan (2014), Gollin et al. (2014a), Adamopoulos and Restuccia (2014), Tombe (2015), Adamopoulos and Restuccia (2015), Gottlieb and Grobovšek (2015), and Chen (2016), among others.

${ }^{4}$ The stylized fact of agricultural capital intensity differences holds even if capital is measured in physical quantities. Hence, the measured differences in capital intensity are not simply due to the differences in the quality of capital, as emphasised in Caunedo and Keller (2016).

${ }^{5}$ See, for example, Hansen and Prescott (2002) and Ngai (2004), among others.
} 
traditional technology and a modern technology in agriculture, and study how the economy converges to the modern balanced growth path. My paper differs from these works in two ways. First, my motivation for modelling technology adoption is to explain cross-country agricultural productivity differences, instead of long-run growth. Second, I model heterogeneous farmers and study technology adoption at the farm level. Modelling heterogeneity allows me to empirically match the technology adoption curve observed in the data. It also allows me to study the role of land misallocation and its negative impact on technology adoption. Hence, my paper also contributes to both the technology adoption literature and the literature studying land misallocation in agriculture. ${ }^{6}$

The paper proceeds as follows. Section 2 describes both cross-country and U.S. historical stylized facts on capital intensity in agriculture. Section 3 describes the model. Section 4 discusses the calibration strategy. Section 5 shows my results of the quantitative analysis. Section 6 concludes the paper.

\section{Evidence on Capital Intensity}

I document two stylized facts of agricultural capital intensity. First, capital intensity differences across countries are especially prominent in the agricultural sector. Second, historically in the U.S., capital intensity is seen to increase much faster in agriculture than in non-agriculture. I show that these patterns are consistent with the trend of agricultural technology adoption.

\footnotetext{
${ }^{6}$ See, for example, Parente and Prescott (1994) and Comin and Hobijn (2010) for technology adoption, and Ayerst (2016) for the impact of misallocation on technology adoption. The misallocation literature includes, for example, Restuccia and Rogerson (2008) and Hsieh and Klenow (2009), and in particular the literature studying misallocation in agriculture includes, for example, Adamopoulos and Restuccia (2015), Restuccia and Santaeulalia-Llopis (2015), and Adamopoulos et al. (2016).
} 


\subsection{Agricultural Capital Intensity across Countries}

\subsubsection{Data}

I construct a dataset on sectoral capital intensity that are comparable across countries. I first use data from the World Bank (Larson et al., 2000), which provide estimates of capital stocks for both agricultural and non-agricultural sectors across 62 countries, covering both rich and poor ones, for the years 1967 - 1992. The capital stocks data are, however, measured in local price. To obtain real measure that is comparable across countries, I adjust for local price of capital using price data from the Penn World Table 8.0 (Feenstra et al., 2015). I next estimate the sectoral real value-added, following the procedure described in Caselli (2005) and Gottlieb and Grobovšek (2015) and combining data from two different sources: 1) data from the World Development Indicators (WDI) on nominal sectoral value-added with associated price data, and 2) data from the Food and Agricultural Organization (FAO) on real agricultural gross output with associated price data. I combine data for sectoral capital and output to calculate capital-output ratios at the sectoral level. Additionally, I calculate capital-labour ratios using employment data from the FAO and the Penn World Table 8.0. See the data appendix for a detailed description of data sources as well as calculation methodology.

As a robustness check, I also calculate sectoral capital-output ratios using the World Input-Output Database (Timmer et al., 2015). This database provides a balanced panel of capital-output ratios across countries, which is suitable for regression analysis. The caveat to using this dataset is, however, that it mainly covers rich and middle-income countries, while my dataset has better coverage of poor countries. Hence, I only use the WIOD data as a robustness check. 
Figure 1: The Capital Intensity across Countries

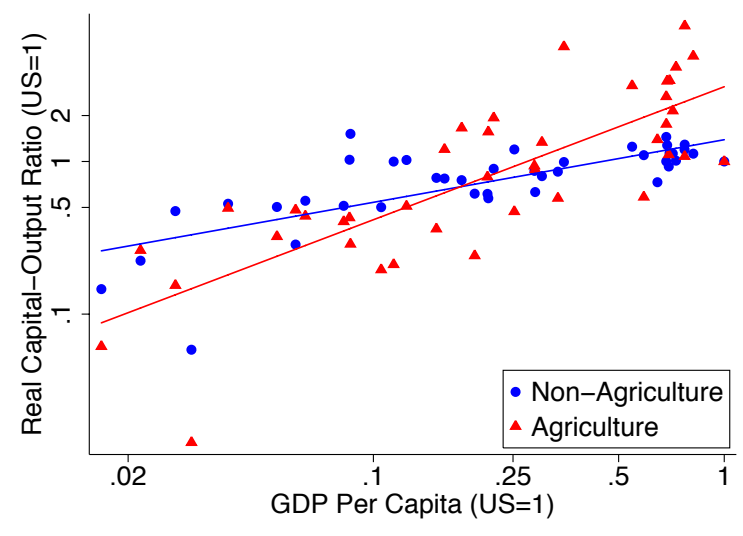

(a) Capital-Output Ratio

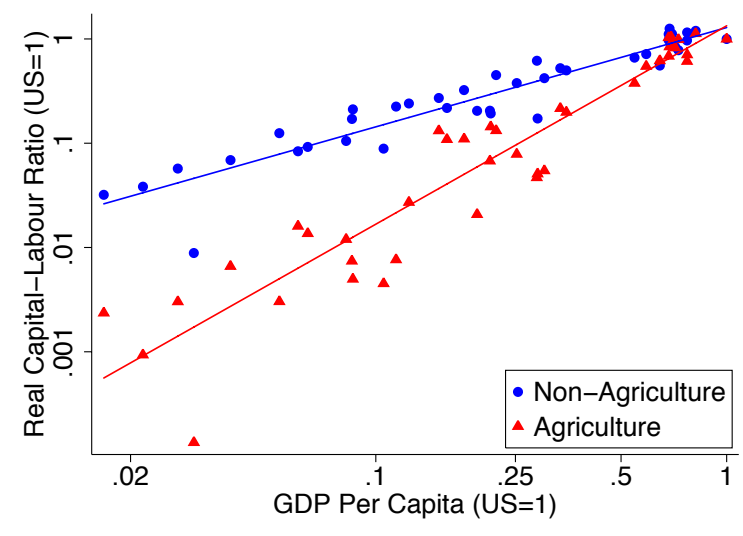

(b) Capital-Labour Ratio

Note:

[1] The capital-output ratio, capital-labour ratio, and GDP per capita are normalized relative to the U.S. and are in log scale.

[2] Capital and output are real measures with common prices across countries.

[3] The slopes of the fitted lines in the left figure are 0.87 and 0.41 for agriculture and non-agriculture, respectively. The slopes in the right figure are 1.90 and 0.95 for agriculture and non-agriculture, respectively. [4] These figures are from the author's calculation combining different sources. See the data appendix for a detailed description.

Figure 2: Nominal Capital-Output Ratio

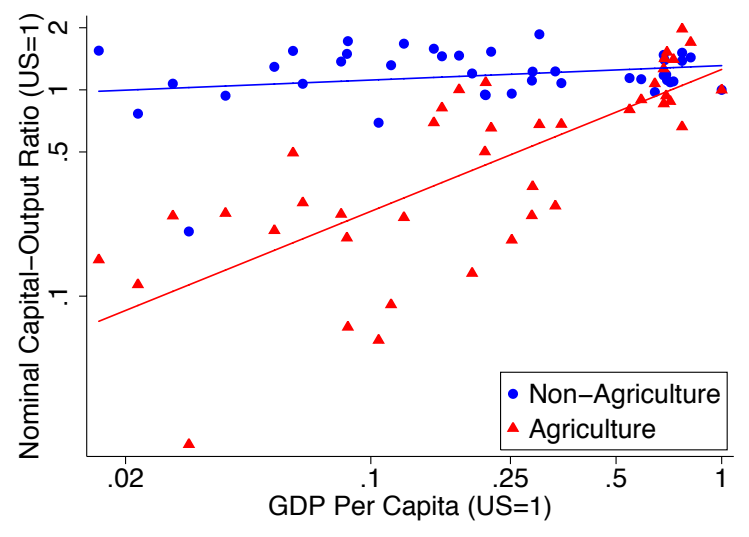

Note:

[1] Capital-output ratio and GDP per capita are normalized relative to the U.S. and are in log scale for illustration purposes.

[2] Capital and output are nominal measures with local prices.

[3] The slopes of the fitted lines are 0.69 and 0.07 for agriculture and non-agriculture, respectively.

[4] These figures are from the author's calculation combining different sources. See the data appendix for a detailed description. 


\subsubsection{International Patterns of Capital Intensity}

It is well-known that, relative to rich countries, poor countries have lower capital intensity, measured as real capital-output ratio or capital-labour ratio (Hsieh and Klenow, 2007). ${ }^{7}$ What is less well-known is that these differences are larger in the agricultural sector than in the non-agricultural sector. Figure 1 shows the real capital-output ratio and capitallabour ratio across countries, for both the agricultural and non-agricultural sectors. The figure illustrates the first stylized fact: richer countries have higher capital-output ratio and capital-labour ratio in both sectors, but the differences in agriculture are much larger. For example, the non-agricultural capital-labour ratio differs by around 10-fold between the U.S. and the $20 \%$ poorest countries in my sample, while the agricultural capital-labour ratio differs by 165 -fold. ${ }^{8}$

Figure 2 compares the nominal capital-output ratio, measured using local prices, across countries. While the nominal capital-output ratio in the non-agricultural sector is roughly the same across countries, it differs substantially in the agricultural sector. As I will discuss later in this section, this fact provides evidence that the aggregate production function of the agricultural sector may not be summarized by a single Cobb-Douglas form with a constant capital share.

I further confirm this stylized fact in a cross-country regression using both my constructed data and the WIOD data. Let $\Delta \frac{K}{Y}=\log \frac{K_{a}}{Y_{a}}-\log \frac{K_{n}}{Y_{n}}$ denote the difference of capital-output ratios between agriculture and non-agriculture within a country, measured either in nominal or real terms. I regress this variable on countries' real GDP per capita, time dummies, and country dummies. The results are displayed in Table 1: the capital-output ratio of

\footnotetext{
${ }^{7}$ In cross-country analysis, real means that capital and output are measured using common international prices, while nominal means they are measured in local prices. This is in contrast to the time series analysis in the next stylized fact, where nominal means that capital and output are measured using current prices instead of constant prices.

${ }^{8}$ The $20 \%$ poorest countries in my sample are El Salvador, Malawi, Tanzania, Madagascar, India, Kenya, Egypt, and Pakistan, sorted by their real GDP per capita.
} 
Table 1: Capital-output Ratio across Countries

\begin{tabular}{lcccccc}
\hline Dependent & \multicolumn{3}{c}{ Constructed Dataset } & \multicolumn{3}{c}{ WIOD Data } \\
Variable $\Delta K / Y$ & $(1)$ & $(2)$ & $(3)$ & $(4)$ & $(5)$ & $(6)$ \\
\hline Log GDP & $0.66^{* *}$ & $0.31^{* *}$ & $0.43^{* *}$ & $0.56^{* *}$ & $0.41^{* *}$ & 0.19 \\
& $(0.03)$ & $(0.09)$ & $(0.03)$ & $(0.07)$ & $(0.03)$ & $(0.14)$ \\
Time Dummy & & $\checkmark$ & & $\checkmark$ & & $\checkmark$ \\
Country Dummy & & $\checkmark$ & & $\checkmark$ & & $\checkmark$ \\
Measurement of $\Delta K / Y$ & Nominal & Nominal & Real & Real & Nominal & Nominal \\
\hline
\end{tabular}

Note:

[1] The data are from the World Bank (Larson et al., 2000) and the World Input-Output Database (Timmer et al., 2015).

[2] I regress $\Delta \frac{K}{Y}\left(\log \left(\frac{K_{a}}{Y_{a}}\right)-\log \left(\frac{K_{n}}{Y_{n}}\right)\right)$ on $\log$ GDP per capita (PPP), country dummies and time dummies. Standard errors are in bracket.

[3] Nominal measure means capital and output are measured using local price; real measure uses international comparable prices.

agriculture increases with GDP per capita relative to that of the non-agricultural sector, under both nominal and real measures, consistent with Figure 1 and Figure 2. Therefore, it is a robust fact that the cross-country differences of capital intensity are larger in the agricultural sector than in the non-agricultural sector.

This fact is consistent with evidence in international differences in agricultural technology from the Cross-Country Historical Adoption of Technology (CHAT) data set, which is an extension of the data described in Comin and Hobijn (2004). According to the CHAT dataset, the aforementioned $20 \%$ poorest countries in my dataset have on average only 1.40 tractors per 1000 hectares, compared to 10.96 tractors in the U.S. Similarly, agricultural harvester machines also differ by around 14-fold. Therefore, rich and poor countries differ in the organization of agricultural production, as reflected by differences in agricultural capital intensity and usage of modern machinery inputs. 
Figure 3: The Capital-Output Ratio in the U.S.

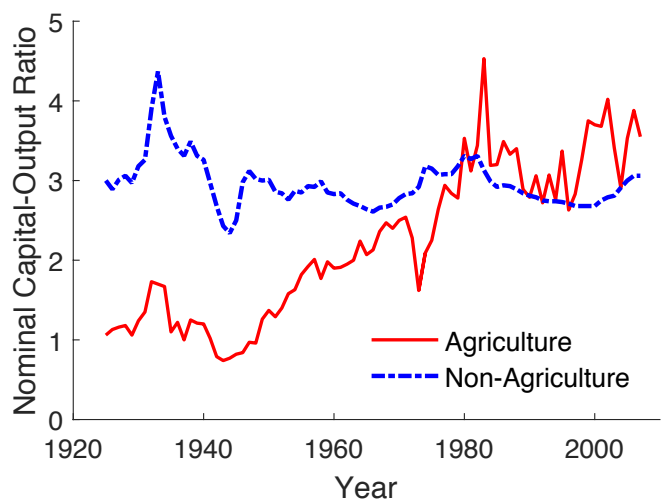

Note: The capital-output ratio is measured using current prices and the data are from the U.S. Bureau of Economic Analysis (BEA). Please see the data appendix for the source of the data.

Figure 4: U.S. Technology Adoption, 1920-2007

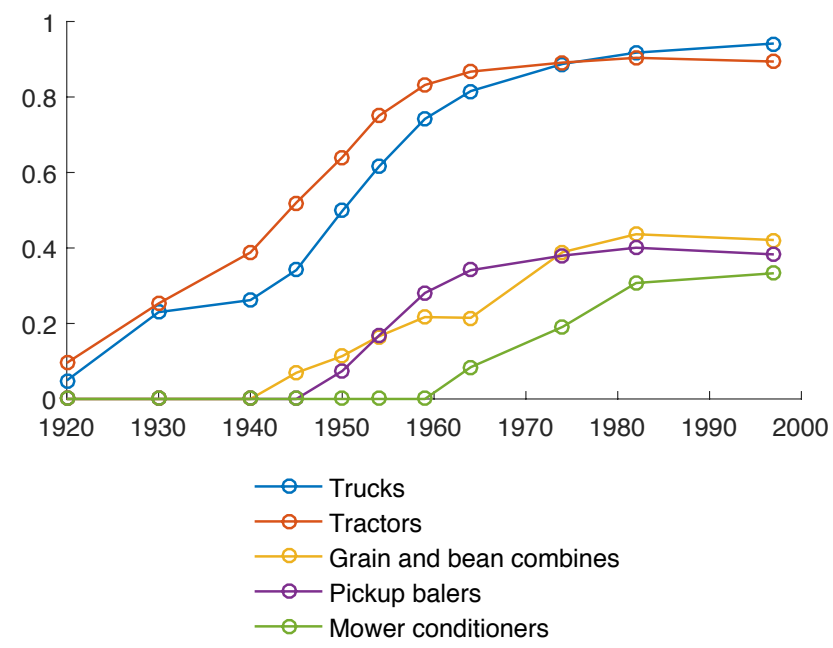

Note: [1] The figure shows the percentage of agricultural output produced by farms with modern machinery. [2] The data are from the U.S. Census of Agriculture (USCA hereafter). Please see the data appendix for a detailed description of the data. 


\subsection{U.S. Agricultural Capital Intensity over Time}

The second stylized fact is that, in the United States, capital intensity increases faster in the agricultural sector than in the non-agricultural sector in the twentieth century. Figure 3 shows the capital-output ratio in the U.S. of both agricultural and non-agricultural sectors, which are from the U.S. Bureau of Economic Analysis (BEA). ${ }^{9}$ We can see that while the capital-output ratio (measured in current prices) is stable in the non-agricultural sector, which is consistent with the Kaldor facts, it increases over time in the agricultural sector. The increasing agricultural capital intensity comes from the postwar period of mechanization in the U.S. agricultural sector. Figure 4 shows the percentage of agricultural output produced by farms with modern machinery, such as trucks, tractors, and combines, in the U.S. starting from 1920. Machinery usage increases rapidly between 1940 and 1980, which is also the period that agricultural capital intensity increases relative to the non-agricultural sector. ${ }^{10}$

The nominal capital-output ratio, measured at current prices, is particularly important. The nominal capital-output ratio, calculated as the capital share divided by the rate of return of capital. According to the Kaldor facts, the rate of return is roughly stable over time. If the agricultural sectoral production function is Cobb-Douglas, then the capital share should also be constant. Together, these two constants would render the capital-output ratio constant, which contradicts the observed pattern in Figure 3. This suggests that the assumption of a Cobb-Douglas production function with constant capital share in agriculture, which is often made in the literature, is inconsistent with the data. Therefore, in the following section I introduce a model which allows for multiple technologies in agriculture, featuring technology adoption and capital deepening. My model predicts increasing agricultural capital-output ratio over time, consistent with the stylized facts. ${ }^{11}$

\footnotetext{
${ }^{9}$ Note that the data from the BEA have already account for quality improvements. See Chapter 4 of the National Income and Product Accounts (NIPA) Handbook.

${ }^{10}$ Manuelli and Seshadri (2014) provides an excellent discussion on how tractors replace horses and human labour in agricultural production, in response to the drop in relative price of tractors versus other inputs.

${ }^{11}$ Another explanation, instead of allowing for multiple technologies, is to assume the agricultural sectoral
} 


\section{A Model with Technology Adoption}

I present a two-sector neoclassical growth model featuring technology adoption in agriculture. I describe the model in two steps. First, I consider a static problem where farmers choose between different technologies taking prices as given. Second, I close the model by introducing the dynamic general equilibrium with two sectors, where I lay out the market structure and the representative household's problem on consumption and investment, as well as labour supply to both sectors.

\subsection{Farmers' Problem}

I start by describing the farmer's choice problem between different technologies, taking prices as given. This problem helps us understand the process of technology adoption, which is a key component of my model. Since this problem is static, I omit the time subscript $t$ to simplify notation.

There is a measure $N_{a}$ of farmers in the economy, who can produce the agricultural good on their farms and sell it at price $p$. Each farmer operates one farm, and is endowed with one unit of labour in each period and supplies it inelastically to the farm. Farmers differ in their farming ability $s \in F(s)$. This ability can be interpreted as knowledge of crop cultivation, managerial talent of the farming business, or even the physical strength.

\subsubsection{Traditional and Modern Technologies}

The agricultural good can be produced using two alternative technologies: a traditional technology that is less capital intensive and a modern technology that is more capital intensive.

production function has the feature that the elasticity of substitution between capital and labour is different from unity (Alvarez-Cuadrado et al., 2015). In the appendix, I show that my conjecture does not conflict with this view: the agricultural production in my model also aggregates to a technology with the elasticity different from unity. My conjecture of mechanization actually provides a micro foundation for AlvarezCuadrado et al. (2015) why the elasticity is greater than unity in the aggregate production function in the agricultural sector. 
Consider a farmer with ability $s$. He can operate a farm with the traditional technology given by

$$
y=A \kappa s^{1-\alpha_{r}-\gamma_{r}} k^{\alpha_{r}} l^{\gamma_{r}}
$$

where $y$ is the farm's output, $A$ is the economy-wide productivity, $\kappa$ is the agriculturalspecific productivity (such that $A$ and $\kappa$ are common to all farms), $k$ and $l$ are the capital and land inputs of the farm, and $\alpha_{r}$ and $\gamma_{r}$ are the capital and land shares of the traditional technology. Following the literature, I assume that farms use labour input from the farmer only, which is $s$ in efficiency units, and does not hire any off-farm labour. ${ }^{12}$ The profit of operating a traditional farm is given by

$$
\pi_{r}(s)=\max _{\{k, l\}}\left\{p A \kappa s^{1-\alpha_{r}-\gamma_{r}} k^{\alpha_{r}} l^{\gamma_{r}}-p^{k} r k-q l\right\}
$$

where $r$ and $q$ are the rental rates of capital and land, and $p^{k}$ is the price of the capital good.

The farmer can also choose to operate a farm with modern technology given by

$$
y=A B \kappa s^{1-\alpha_{m}-\gamma_{m}} k^{\alpha_{m}} l^{\gamma_{m}}
$$

where $\alpha_{m}$ and $\gamma_{m}$ are the capital and land shares of the modern technology, and $B$ measures the relative productivity difference between the traditional and the modern technologies. I assume $\alpha_{m}>\alpha_{r}$ since modern technology is more capital intensive. It is then natural to assume that the traditional technology is more labour and land intensive, which implies $\gamma_{m}<\gamma_{r}$ and $1-\alpha_{m}-\gamma_{m}<1-\alpha_{r}-\gamma_{r}$. The profit of operating a modern farm is given by

$$
\pi_{m}(s)=\max _{\{k, l\}}\left\{p A B \kappa s^{1-\alpha_{m}-\gamma_{m}} k^{\alpha_{m}} l^{\gamma_{m}}-p^{k} r k-q l\right\}
$$

Choosing the modern technology incurs a fixed cost of $f$ units of capital good in every

\footnotetext{
${ }^{12}$ I focus on family farms and abstract from hiring labour decision, following Adamopoulos and Restuccia (2014) and Chen (2016). In the data, labour hired by farms is usually difficult to measure due to issues such as unauthorized labour. Furthermore, evidence suggests that hired labour is relatively limited in quantity compared to family labour. Table 3.5 of the Report on the 1990 World Census of Agriculture shows that, among the 55 countries reported, each farm on average uses 5.26 household member workers, and only 0.2 outside-hired workers who work more than 6 months of the year.
} 
period. This fixed cost can be interpreted as indivisibility of equipment, up-front investment in learning, or the required infrastructure of modern technology. This assumption of fixed cost associated with technology choice is widely used in the literature, such as Helpman et al. (2004) and Adamopoulos and Restuccia (2015). Sunding and Zilberman (2001) survey literature studying technology adoption in agriculture, and find that this fixed cost assumption does capture the salient features of agricultural technology adoption observed in the data. I model this fixed cost as a per period cost, but we can also view it as a one-time up-front fixed cost that is financed over multiple periods. ${ }^{13}$

\subsubsection{Technology Choice}

A farmer with ability $s$ will choose the modern technology if and only if the profit from using the modern technology exceeds that of using the traditional technology by at least the value of the fixed cost:

$$
\Delta \pi(s)=\pi_{m}(s)-\pi_{r}(s) \geqslant p^{k} f
$$

The difference in profits is linear in the farmer's ability $s: \Delta \pi(s)=\pi^{m}(s)-\pi^{r}(s)=$ $s \Omega\left(p, q, r, p^{k}\right)$, where $\Omega$ is a function of prices independent of $s$. Therefore, Equation (1) can be rewritten as

$$
\Delta \pi(s)=s \Omega \geqslant p^{k} f
$$

There are two possible scenarios associated with technology adoption. Scenario (1): $\Omega>0$, so that $\pi_{m}(s)-\pi_{r}(s)=s \Omega>0$ for any farmer. I plot this scenario in the left panel of Figure 5, where the profit functions are plotted against farmer ability. Modern technology is potentially more profitable than traditional technology for all farmers (the line of $\pi_{m}$ is always above the line of $\pi_{r}$ ), but the fixed cost reduces the actual payoff of the modern technology (the line of $\pi_{m}$ shifts down to $\pi_{m}-p^{k} f$ ). As a result, only high-ability farmers whose farms

\footnotetext{
${ }^{13}$ As will be clear later, since there is no financial friction in this model, these two setups are equivalent.
} 
Figure 5: Technology Choice
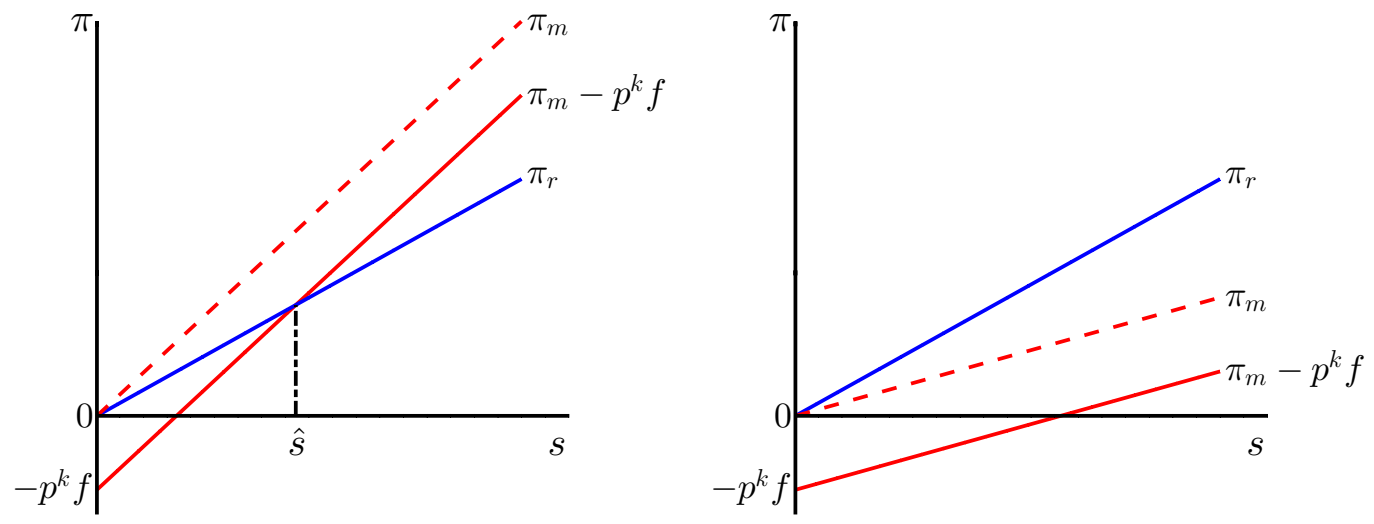

are large enough can afford the fixed cost and adopt the modern technology. Let us denote the cut-off ability as $\hat{s}$ such that, given the fixed cost, a farmer with $s=\hat{s}$ is indifferent between the two technologies. This requires $\hat{s} \Omega=p^{k} f$, or $\hat{s}=\frac{p^{k} f}{\Omega}$. All farmers above this threshold $(s \geqslant \hat{s})$ choose modern technology, and farmers below it choose traditional technology. Therefore, the fraction of farmers who adopt modern technology is given by

$$
\mathscr{F}=1-F(\hat{s})=1-F\left(\frac{p^{k} f}{\Omega}\right)
$$

Scenario (2): if $\Omega<0$, then Equation (2) can never be satisfied and the modern technology will not be adopted by any of the farmers $(\mathscr{F}=0)$. This scenario is illustrated in the right panel of Figure 5. To summarize, the fraction of farmers who adopt the modern technology can be written as

$$
\mathscr{F}=\left\{\begin{array}{l}
1-F\left(\frac{p^{k} f}{\Omega}\right), \quad \text { if } \Omega>0 \\
0, \quad \text { otherwise. }
\end{array}\right.
$$

Denote farmer choice of technologies as a dummy variable $D(s)$, where $D(s)=1$ represents the choosing of modern technology given farmer ability $s$. Using this, we can rewrite 
the farming profit as

$$
\pi(s)=\max _{D(s) \in\{0,1\}}\left\{D(s)\left(\pi_{m}(s)-p^{k} f\right)+(1-D(s)) \pi_{r}(s)\right\} .
$$

\subsubsection{Comparative Statistics}

Equation (3) provides summary statistics on technology adoption. The following lemma helps to show how productivities and prices affect adoption. The proof is in the appendix.

Lemma 1. The fraction of farmers using the modern technology $\mathscr{F}$ has the following properties: $\mathscr{F}_{B}^{\prime} \geqslant 0, \mathscr{F}_{r}^{\prime} \leqslant 0, \mathscr{F}_{p^{k}}^{\prime} \leqslant 0$, and $\mathscr{F}_{q}^{\prime} \geqslant 0$.

Recall that $B$ measures the relative productivity between modern and traditional technology. Intuitively, the adoption of modern technology increases with its relative productivity $\left(\mathscr{F}_{B}^{\prime} \geqslant 0\right)$. Since modern technology is more capital intensive, higher capital costs would deter adoption $\left(\mathscr{F}_{r}^{\prime} \leqslant 0\right.$ and $\left.\mathscr{F}_{p^{k}}^{\prime} \leqslant 0\right)$. Similarly, since traditional technology is more land intensive, a higher land cost makes traditional technology less appealing to farmers and facilitates adoption of modern technology $\left(\mathscr{F}_{q}^{\prime} \geqslant 0\right)$. In long-run economic development, we typically find that cost of capital $\left(p^{k} r\right)$ decreases and relative productivity of modern technology $(B)$ increases. As modern technology becomes more profitable over time, it gradually replaces the traditional technology ( $\hat{s}$ decreases and $\mathscr{F}$ increases).

\subsection{Dynamic General Equilibrium}

Having described the farmers' problem, I close the model by introducing a simple two-sector dynamic general equilibrium.

\subsubsection{Two Sectors}

There are two sectors in this economy: an agricultural sector and a non-agricultural sector. In the agricultural sector, farmers of heterogeneous ability produce the agricultural good 
on their farms as described before. The agricultural good is priced at $p_{t}$ and is used for consumption only.

In the non-agricultural sector, there is a representative firm that employs capital $\tilde{K}_{n t}$ and labour $\tilde{N}_{n t}$ to produce the non-agricultural good $Y_{n t}$ :

$$
Y_{n t}=A_{t} \tilde{K}_{n t}^{\alpha_{n}} \tilde{N}_{n t}^{1-\alpha_{n}}
$$

where $A_{t}$ is the economy-wide TFP (common to both agriculture and non-agriculture), and $\alpha_{n}$ is the capital share in the non-agricultural sector. Let the non-agricultural good be the numeraire with its price normalized to one.

The non-agricultural good can either be used for consumption or transformed into capital through a linear technology, following Greenwood et al. (1997). Let $v_{t}$ denote this investmentspecific technology: 1 unit of non-agricultural good can be transformed into $v_{t}$ units of capital good. Therefore, the price of capital good is given by $p_{t}^{k}=\frac{1}{v_{t}}$.

\subsubsection{The Representative Household's Problem}

There is a measure one of infinitely-lived representative household in this economy. This household has $N_{t}$ members in period t and grows at a rate of $n$. Each household member is endowed with one unit of time in each period that is supplied inelastically to the labour market. The household allocates $N_{a t}$ of its members to be farmers in the agricultural sector and the remaining $N_{n t}=N_{t}-N_{a t}$ to be workers at the representative firm in the nonagricultural sector. Farmers are heterogeneous in their farming ability $s$ and each earn farming profit $\pi(s)$. Workers are, however, homogeneous and earn the same wage $w$ subject to a tax rate $\xi$. I use this tax to capture the labour mobility barrier between sectors, which is also used in Adamopoulos and Restuccia (2014) and Chen (2016). I will discuss this barrier in detail in the calibration. The tax revenue is rebated to the household so it does not affect 
aggregate demand. The total household labour income is given by

$$
N_{n t} w_{t}(1-\xi)+N_{a t} \int_{s \in S} \pi_{t}(s) F(d s)
$$

where the first term represents income from workers and the second term is that from farmers.

I follow Adamopoulos and Restuccia (2014) in abstracting from selection in occupational choice. In other words, the household only determines the fraction of its members working in agriculture without selecting on the basis of ability. This assumption keeps the distribution of farmer ability constant across time and across country. Lagakos and Waugh (2013) study self-selection in depth and show that it aggravates agricultural productivity differences across countries. Since selection is well understood in the literature, I abstract from it in this paper to keep my model tractable.

The household derives its utility from consuming both the agricultural good and the non-agricultural good:

$$
U=\sum_{t=0}^{\infty} \beta^{t}\left[\phi \log \left(c_{a t}-\bar{a}\right)+(1-\phi) \log \left(c_{n t}\right)\right] N_{t}
$$

where $\beta$ is the discount factor, $\phi$ is a preference weight of the agricultural good, and $\bar{a}$ is a subsistence requirements for agricultural consumption. Consumption of each good in period $t$ is denoted by $c_{a t}$ and $c_{n t}$, respectively.

The household's total income is the sum of labour income, capital income, and land income:

$$
\left(N_{t}-N_{a t}\right) w_{t}(1-\xi)+\int_{s \in S} \pi_{t}(s) F(d s) N_{a t}+p_{t}^{k} r_{t} k_{t}+q_{t} L+T_{t}, \quad \forall t
$$

where $L$ and $k_{t}$ are total household land endowment and capital stock, and $T_{t}$ is the household rebate from labour income tax which equals $\left(N_{t}-N_{a t}\right) w_{t} \xi$ in equilibrium. This household divides its total income into consumption and investment each period:

$$
\left(p_{t} c_{a t}+c_{n t}\right) N_{t}+p_{t}^{k} x_{t}=\left(N_{t}-N_{a t}\right) w_{t}+\int_{s \in S} \pi_{t}(s) F(d s) N_{a t}+p_{t}^{k} r_{t} k_{t}+q_{t} L+T_{t}, \quad \forall t
$$


The first term $\left(p_{t} c_{a t}+c_{n t}\right) N_{t}$ denotes the consumption expenditure of period $t$, and the second term $p_{t}^{k} x_{t}$ is the investment expenditure, which increases the capital stock for the next period:

$$
k_{t+1}=(1-\delta) k_{t}+\frac{x_{t}}{\pi}
$$

Here $\pi$ is the barrier to investment: I follow Ngai (2004) and Restuccia (2004) by assuming that one unit of investment increases capital stock by $\frac{1}{\pi}$ units. Therefore, this parameter $\pi$ captures the distorted prices for capital typically observed in poor countries (Restuccia and Urrutia, 2001). ${ }^{14}$

\subsubsection{The Competitive Equilibrium}

I focus on the competitive equilibrium of this economy, which is defined as follows.

Definition 1. Given $K_{0}$, the competitive equilibrium consists of sequences of consumption $\left\{c_{a t}, c_{n t}\right\}_{t=0}^{\infty}$, investments $\left\{x_{t}\right\}_{t=0}^{\infty}$, farm inputs and outputs $\left\{k_{t}(s), l_{t}(s), y_{t}(s), \forall s \in S\right\}_{t=0}^{\infty}$, prices of the agricultural and capital goods $\left\{p_{t}, p_{t}^{k}\right\}_{t=0}^{\infty}$, wages $\left\{w_{t}\right\}_{t=0}^{\infty}$, interest rates $\left\{r_{t}\right\}_{t=0}^{\infty}$, non-agricultural inputs and outputs of the representative firm $\left\{\tilde{K}_{n t}, \tilde{N}_{n t}, Y_{n t}\right\}_{t=0}^{\infty}$, aggregate capital stocks in the economy $\left\{K_{t}\right\}_{t=0}^{\infty}$, and measures of agricultural employment $\left\{N_{a t}\right\}_{t=0}^{\infty}$, such that

- Given prices, interest rates and wages, the representative household maximizes its utility by choosing the optimal levels of consumption, investment, and agricultural employment share $\left\{c_{a t}, c_{n t}, x_{t}, k_{t+1}, N_{a t}\right\}_{t=0}^{\infty}$.

- Given prices, interest rates and wages, the representative firm in the non-agricultural sector maximizes its profit by choosing $\left\{\tilde{K}_{n t}, \tilde{N}_{n t}\right\}_{t=0}^{\infty}$.

\footnotetext{
${ }^{14}$ Technically, a change in $\pi$ is similar to a change in the level of $\left\{v_{t}\right\}_{t=0}^{\infty}$ in affecting the cost of capital. Later in the quantitative analysis, I assume the investment-specific technology $\left\{v_{t}\right\}_{t=0}^{\infty}$ is common to all countries, while this barrier $\pi$ is country-specific and time-invariant.
} 
- Given prices and interest rates, farmers maximize farming profit by choosing the optimal level of inputs and outputs $\left\{k_{t}(s), l_{t}(s), y_{t}(s), \forall s \in S\right\}_{t=0}^{\infty}$.

- All markets clear:

- Agricultural good:

$$
c_{a t} N_{t}=N_{a t} \int_{s} y_{t}(s) F(d s), \quad \forall t
$$

- Non-agricultural good:

$$
c_{n t} N_{t}+\frac{x_{t}}{v_{t}}+\frac{\int_{s} f D(s) F(d s)}{v_{t}}=\tilde{Y}_{n t}, \quad \forall t,
$$

where $D(s)$ is a dummy indicating technology adoption choice and $\int_{s} f D(s) F(d s)$ is the aggregate expenditure on the fixed cost of technology adoption.

- Capital market:

$$
N_{a t} \int_{s} k_{t}(s) F(d s)+\tilde{K}_{n t}=K_{t}=k_{t}, \quad \forall t
$$

- Labour market:

$$
N_{a t} \int_{s} F(d s)+\tilde{N}_{n t}=N_{t}, \quad \forall t
$$

- Land market:

$$
N_{a t} \int_{s} l_{t}(s) F(d s)=L, \quad \forall t
$$

\subsubsection{Characterization of the Dynamic Equilibrium}

Although this model may seem complex, its dynamic properties are similar to a standard onesector neoclassical growth model. In this section, I show how the model can be aggregated.

In each period, let $c_{t}$ denote the household's per capita consumption. It can be shown that the consumption of each good satisfies

$$
c_{a t}=\phi \frac{c_{t}-p_{t} \bar{a}}{p_{t}}+\bar{a} \quad \text { and } \quad c_{n t}=(1-\phi)\left(c_{t}-p_{t} \bar{a}\right)
$$


and the indirect utility function is given by

$$
\tilde{u}\left(c_{t}, p_{t}\right)=\log \left(c_{t}-p_{t} \bar{a}\right)-\phi \log p_{t}+\log \left(\phi^{\phi}(1-\phi)^{1-\phi}\right) .
$$

The household also chooses $N_{a t}$ to maximize its labour income $N_{a t} \int_{s \in S} \pi_{t}(s) F(d s)+\left(N_{t}-\right.$ $\left.N_{a t}\right)(1-\xi) w_{t}$. The first order condition implies

$$
(1-\xi) w_{t}=\int_{s \in S} \pi_{t}(s) F(d s)
$$

Therefore, the total labour income of the household can be written as

$$
\left(N_{t}-N_{a t}\right)(1-\xi) w_{t}+N_{a t} \int_{s \in S} \pi_{t}(s) F(d s)=N_{t}(1-\xi) w_{t}
$$

With Equation (5) and (7), we can rewrite the household's problem as

$$
\begin{gathered}
\max _{c_{t}, x_{t}} \sum_{t=0}^{\infty} \beta^{t} N_{t} \tilde{u}\left(c_{t}, p_{t}\right), \\
\text { s.t. } \quad N_{t} c_{t}+p_{t}^{k} x_{t}=(1-\xi) w_{t} N_{t}+p_{t}^{k} r_{t} k_{t}+q_{t} L, \\
k_{t+1}=(1-\delta) k_{t}+\frac{x_{t}}{\pi} .
\end{gathered}
$$

This problem is identical to that of a standard one-sector neoclassical growth model with the familiar Eular equation written as

$$
\tilde{u}_{c}\left(c_{t}, p_{t}\right)=\beta \tilde{u}_{c}\left(c_{t+1}, p_{t+1}\right)\left(\frac{r_{t+1}}{\pi}+1-\delta\right) \frac{p_{t+1}^{k}}{p_{t}^{k}} .
$$

This equation implies a period $t+1$ interest rate of

$$
\begin{aligned}
& r_{t+1}=\pi\left[\frac{\tilde{u}_{c}\left(c_{t}, p_{t}\right)}{\tilde{u}_{c}\left(c_{t+1}, p_{t+1}\right)} \frac{p_{t}^{k}}{p_{t+1}^{k}} \frac{1}{\beta}-(1-\delta)\right] \\
& =\pi\left[\frac{c_{t+1}-p_{t+1} \bar{a}}{c_{t}-p_{t} \bar{a}} \frac{v_{t+1}}{v_{t}} \frac{1}{\beta}-(1-\delta)\right]=\pi\left[\frac{g_{t}^{c} g_{t}^{v}}{\beta}-(1-\delta)\right],
\end{aligned}
$$

where $g_{t}^{c}$ and $g_{t}^{v}$ denote the growth rates of excess consumption (total consumption less subsistence requirements) and the investment-specific technology $v_{t}$, respectively.

Although the aggregate growth of my model is similar to that of the neoclassical growth model, it has two distinct features in the long-run growth. First, with economic development, 
there will be ongoing structural transformation, where employment is reallocated from the agricultural sector to the non-agricultural sector. This structural transformation is driven by the subsistence requirement $\bar{a}$. As labour productivity improves in the agricultural sector, fewer resources are required to produce $\bar{a}$, and therefore a greater portion of the labour force can be reallocated to the non-agricultural sector. This driving force of structural transformation is first studied in Kongsamut et al. (2001) and supported by empirical evidence in Herrendorf et al. (2014). Second, the investment-specific technology $v_{t}$ plays a larger role in my model than in the standard neoclassical growth model. In the neoclassical growth model, the economy-wide TFP and the investment-specific technology have similar impact

on labour productivity. In my model, however, an improvement in $v$ reduces the cost of capital and benefits farmers with modern technology more than farmers with traditional technology, thus promoting technology adoption. This is in contrast with economy-wide TFP, which affects farmers neutrally, regardless of technology choice.

\section{Calibration}

I calibrate the model to the U.S. historical data. The model successfully replicates both the mechanization process of the U.S. agricultural sector as well as the economy's long run growth. I then use this calibrated model to perform cross-country analysis in the next section.

\subsection{Parameters and Targets}

I calibrate my model to historical data of the U.S. economy encompassing the entire twentieth century (1900 to 2000). This century saw impressive mechanization in the agricultural sector of the U.S. economy. During this period, the price of capital decreased relative to labour, and capital intensity increased in the agricultural sector but barely changed in the non- 
agricultural sector. The historical data for this period provide information on the prevalence of modern technology adoption given prices, productivity changes, and capital intensity changes in agriculture. Therefore, I use historical data to calibrate my model, in particular, to restrict parameters determining technology adoption.

\subsubsection{Time-Invariant Parameters}

The calibration process determines the values of model parameters. Some parameters are time-invariant, while others have a time series of values that change over time. Let me begin by describing how I choose the values of the 12 parameters that are time-invariant, consisting of five parameters determining factor shares $\left(\alpha_{r}, \gamma_{r}, \alpha_{m}, \gamma_{m}, \alpha_{n}\right)$, three parameters determining household's preferences $(\phi, \bar{a}, \beta)$, the barrier to labour mobility $\xi$, the depreciation rate $\delta$, the barrier to investment $\pi$, and one parameter governing the farmer ability distribution $F(s)$. Eight of them $\left(\alpha_{r}, \gamma_{r}, \alpha_{m}, \gamma_{m}, \alpha_{n}, \delta, \pi, \xi\right)$ are directly assigned values that are either common in the literature or from moments that do not depend on the equilibrium. The other four parameters are calibrated by comparing the model's equilibrium moments with data.

Factor Shares: $\alpha_{r}, \gamma_{r}, \alpha_{m}, \gamma_{m}, \alpha_{n}$.-I choose the parameters of the technologies such that the factor shares are consistent with estimations in the literature. I set $\alpha_{m}=0.36$ and $\gamma_{m}=$ 0.18. As a result, the capital, labour, and land shares associated with modern technology are 0.36, 0.46, and 0.18, respectively, consistent with Valentinyi and Herrendorf (2008). Similarly, I set $\alpha_{r}=0.1$ and $\gamma_{r}=0.25$ such that the capital, labour, and land shares associated with traditional technology are $0.10,0.65$, and 0.25 , respectively, consistent with Hayami and Ruttan (1985) and Gollin et al. (2007). Recall that the key assumption of capital deepening is that $\alpha_{m}>\alpha_{r}$ (i.e. modern technology is more capital intensive than traditional technology), which is satisfied in the calibration. The capital share associated 
Figure 6: Ability Distribution

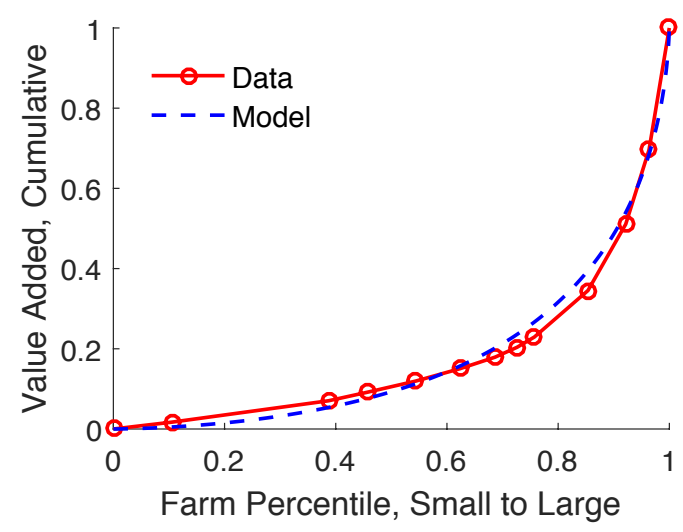

Note: This graph compares the distribution of farm output generated by the model with the data. The data are obtained from Table 58 of the U.S. Census of Agriculture, which sorts farms into different bins according to their size, and calculates the value-added, which corresponds to output in my model, of farms within each bin.

with the non-agricultural sector, $\alpha_{n}$, is set to 0.33 following Gollin (2002).

Preferences: $\phi, \bar{a}, \beta$.-Two preference parameters $\phi$ and $\bar{a}$ govern the agricultural employment share. In particular, when an economy is still in its early stages of development and agricultural productivity is low, agricultural employment share is mainly determined by $\bar{a}$. The term $\phi$, on the other hand, determines agricultural employment share when the economy converges to the asymptotic balanced growth path. I choose the values of these two parameters such that, given agricultural labour productivity for each of 1900 and 2000, agricultural employment share is $33.97 \%$ for 1900 and $1.48 \%$ for 2000 to match the data. ${ }^{15}$ I set the discount rate $\beta=0.96$ to match a capital-output ratio of 3 in the asymptotic balanced growth path.

Ability Distribution.-I assume that farmer ability follows a lognormal distribution $s \in$ $\ln \mathcal{N}\left(0, \sigma_{s}\right)$, with mean normalized to 0 and standard deviation of $\sigma_{s}$. I choose the dispersion parameter $\sigma_{s}=1.33$ such that, once all farmers adopt modern technology, the distribution

\footnotetext{
${ }^{15}$ Please see the data appendix for the detailed information of these moments.
} 
of farm output by farm size best matches the data in the 2007 U.S. Census of Agriculture. ${ }^{16}$ Figure 6 shows that the distribution of farm output in the calibrated model matches the data well.

Barrier to Labour Mobility: $\xi$.-As is well-known for the U.S., the nominal labour productivity of the non-agricultural sector is much higher than that of the agricultural sector. This phenomenon is often referred to as the nominal agricultural productivity gap, following (Gollin et al., 2014b). For example, during the years 1990 - 2000, the relative productivity of non-agriculture (versus agriculture) is on average 1.68. In my model, however, if labour is perfectly mobile between sectors, the relative labour productivity is $\left(1-\alpha_{r}-\gamma_{r}\right) /(1-\alpha)=0.90$ before technology adoption starts and $\left(1-\alpha_{m}-\gamma_{m}\right) /(1-\alpha)=0.69$ after adoption is completed, both of which are considerably smaller than 1.68. To reconcile the relative labour productivity of the model with that of data, I introduce a barrier to labour mobility between the agricultural and non-agricultural sectors. Recall that I assume working in the nonagricultural sector is subject to a wage tax rate $\xi$. I choose $\xi$ to match the 1.68 -fold gap of nominal labour productivity for the years 1990 - 2000, when technology adoption is roughly completed. This requires $\xi=1-0.69 / 1.68=0.59$. Note that although this nominal labour productivity gap between sectors is wider in earlier periods, it turns out that a constant $\xi$ successfully reconciles the gap for the whole historical period (see Figure 9). In other words, my model can endogenously generate the nominal productivity gap that narrows over time. This is because the gap is equal to $1 /(1-\xi)$ multiplied by the ratio of agricultural labour share to non-agricultural labour share (Herrendorf and Schoellman, 2015), and agricultural labour share associated with traditional technology is higher than that of modern technology. Therefore, as modern technology replaces traditional technology, labour share decreases in

\footnotetext{
${ }^{16}$ The census categorizes farms by their size, and then within each category, the census provides the number of farms as well as the total value-added, which corresponds to output, of farms of this category. From this, we can calculate the value-added of farms for each farm size category to obtain an empirical distribution. See the data appendix for a detailed description of this process.
} 
agriculture and the nominal productivity gap narrows as observed in the data. Further note that this barrier $\xi$ is also held constant in the cross-country analysis.

Other Parameters: $\delta, \pi$.- - I follow the literature and set the depreciation rate of capital $\delta$ to be 0.04 . The barrier to investment $\pi$ is normalized to 1 in the benchmark calibration.

\subsubsection{Time Series}

On top of these 12 parameters that are time-invariant, we also need to calibrate seven time series parameters: the endowments of land and labour $\left\{N_{t}, L_{t}\right\}$, the investment-specific technology $\left\{v_{t}\right\}$, the economy-wide and agriculture-specific TFP $\left\{A_{t}, \kappa_{t}\right\}$, the relative productivity between traditional and modern technologies $\left\{B_{t}\right\}$, and the fixed cost of adoption $\left\{f_{t}\right\}$. Note that I use time subscripts $t$ with curly braces to signify time series, to differentiate them from the previous 12 time-invariant parameters. For each time series, we need to determine the level and pattern of growth. I use historical data to restrict the values of each time series. See the data appendix for a detailed description of historical data used in my calibration.

Endowments: $\left\{N_{t}, L_{t}\right\}$.-Endowment values are taken directly from the data. Total land size is stable over time, so I normalize $L_{t}=1$ for all $t$. I normalize population size to 1 for the year 2000, and set the annual population growth rate to be $1.32 \%$, consistent with the population data.

Investment-Specific Technology: $\left\{v_{t}\right\}$.-The investment-specific technology governs the price of the capital good $\left(p^{k}\right)$. Following Greenwood et al. (1997) and Gort et al. (1999), I measure the relative price of investment and durable goods to that of consumption nondurable goods and services, using historical price data from the Bureau of Economic Analysis. Note that the price series from the BEA already take into account the necessary adjustment for quality improvements of capital goods. I normalize the level of $v_{t}$ to be 1 for the year 
Figure 7: Relative Price of Capital Goods

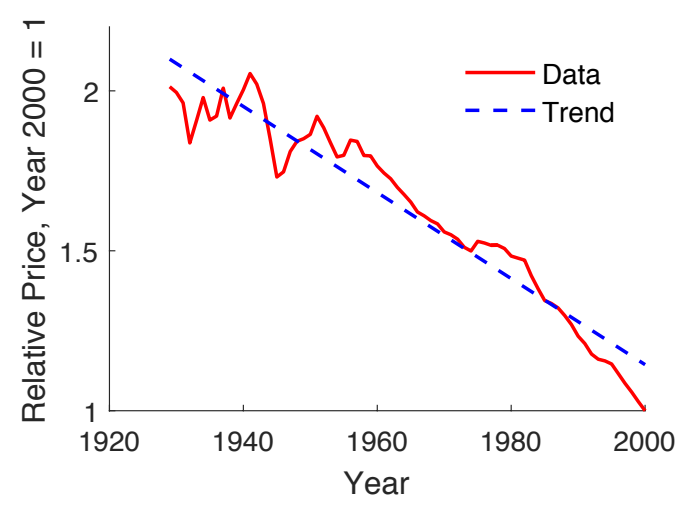

Note:

[1] The red curve shows the relative price of investment and durable goods over consumption non-durable goods and services. The data of price series are from the Bureau of Economic Analysis (BEA) tables. Please see the data appendix for a detailed description of the data.

[2] The blue dashed line is fitted the linear trend of the data, and is used in my calibration.

2000, and choose the sequence such that the implied price series $\left\{p_{t}^{k}\right\}$ decreases over time in a linear pattern as shown in Figure 7. Note that price data are only available after 1929. I extrapolate this price series back to 1900 with the assumption that 1900 - 1929 prices change in the same pattern as observed for 1929 onwards. The results are rather insensitive to the extrapolation method of pre-1929 prices, as this period saw little technology adoption in agriculture. Without technology adoption, the change in the TFP $(A)$ and the change in the investment-specific technology $(v)$ have similar impact on labour productivity, as discussed in Section 3.2.4.

Productivity: $\left\{A_{t}, \kappa_{t}\right\}$.-The economy-wide TFP $\left\{A_{t}\right\}$ and agriculture-specific TFP $\left\{\kappa_{t}\right\}$ are chosen to match sectoral labour productivity over time. I normalize the level of $\left\{A_{t}\right\}$ and $\left\{\kappa_{t}\right\}$ to 1 for the year 2000. I assume they grow at constant rates. The growth rate of $\left\{A_{t}\right\}$ is chosen such that non-agricultural labour productivity increases 6.9-fold between 1900 and 2000. In contrast, agricultural labour productivity increases 30.4-fold over the same period. While technology adoption in my model implies extra growth in agricultural labour productivity, it can only account for a portion of the disparity in labour productivity increase 
between sectors. Using the growth of $\left\{\kappa_{t}\right\}$, I capture the remaining extra agricultural labour productivity growth. For example, self-selection, as studied in Lagakos and Waugh (2013), can amplify productivity growth in agriculture. Although this channel is not explicitly modelled, it is captured by the growth of $\left\{\kappa_{t}\right\}$.

Technology Adoption.-Before we can calibrate the fixed cost of adopting the modern technology $\left\{f_{t}\right\}$ and the relative productivity between modern and traditional technologies $\left\{B_{t}\right\}$, let me briefly describe the technology adoption curve. The adoption curve is defined as a time series indicating the percentage of output produced by farms with modern technology at each period. In the data, there is no indicator variable differentiating farms using modern versus traditional technology. As a proxy, I treat farms with modern machinery as farms with modern technology. The U.S. Census of Agriculture records five kinds of modern machines over time: tractors, trucks, combines, mower conditioners, and pickup balers. I construct, for example, a time series of the percentages of output produced by farms with tractors in each year. I then normalize the value to $100 \%$ for the year 2000 and scale the pre-2000 values accordingly. This time series would represent the adoption curve of tractors. I replicate it for the other four machines, and then take the average of these five adoption curves as my technology adoption curve for the calibration, which is shown in Figure 8. See the data appendix for details.

Now, let us determine the last two series: $\left\{f_{t}\right\}$ and $\left\{B_{t}\right\}$. To reduce the number of free parameters, I restrict the growth rates of these two series to be constant over time, so we only need to determine their levels and growth rates (four parameters in total). These four parameters are chosen such that the technology adoption curve in my model best matches that of the data (see Figure 8). The values for best fit are $f_{1990}=0.75$ decreasing at $3.7 \%$ per year, and $B_{1900}=2.2$ increasing at $0.1 \%$ per year. Although the magnitude of $\left\{f_{t}\right\}$ has little intuition, we can tell that it is not sizeable: for example, in the year 1950 when technology 
Figure 8: Technology Adoption Curve

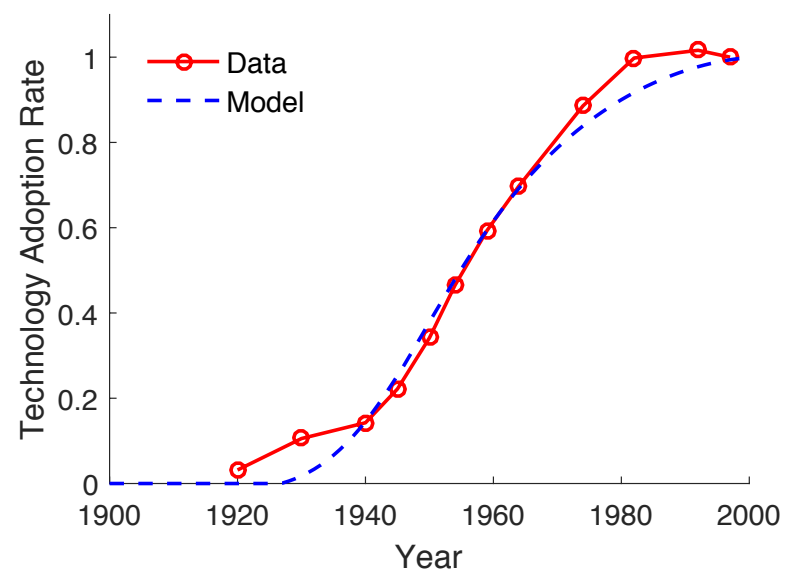

Note: The technology adoption rate of the model is the percentage of output produced using modern technology; the rate in the data is the average percentage of output produced by farms with modern machines. See the text for a detailed description.

adoption is rapid, the fixed cost constitutes on average $4.8 \%$ of farming profit among farmers using modern technology. The magnitude of $\left\{B_{t}\right\}$ is, however, more intuitive: $\left\{B_{t}\right\}>1$ means that the TFP of modern technology is higher than that of traditional technology. $\left\{B_{t}\right\}$ increases over time, indicating that TFP of modern technology increases faster than that of the traditional technology. Note that $\left\{f_{t}\right\}$ and $\left\{B_{t}\right\}$ can be separately identified since the fixed cost $\left\{f_{t}\right\}$ is the same for every farm that adopts modern technology, while relative productivity $\left\{B_{t}\right\}$ affects farms proportionally based on farm size. It follows that, the technology adoption choice of large farms depends more on $\left\{B_{t}\right\}$, while that of smaller farms is more sensitive to $\left\{f_{t}\right\}$.

Table 2 summarizes the values of both time-invariant and time series parameters for the years 1900 and 2000, as well as the main targets for calibration.

\subsection{Model Fit and Discussion}

The calibrated model successfully replicates the historical mechanization process of the U.S. as well as its long-run growth. Figure 8 shows that the model replicates the technology adop- 
Table 2: Summary of Calibration

\begin{tabular}{lll}
\hline Parameter & Value & Moment \\
\hline$\alpha_{r}$ & 0.10 & Capital share (traditional technology) \\
$\gamma_{r}$ & 0.25 & Land share (traditional technology) \\
$\alpha_{m}$ & 0.36 & Capital share (modern technology) \\
$\gamma_{m}$ & 0.18 & Land share (modern technology) \\
$\alpha_{n}$ & 0.33 & Capital share (non-agricultural sector) \\
$\delta$ & 0.04 & Depreciation rate \\
$\pi$ & 1 & Normalization \\
$\bar{c}$ & 0.055 & Agricultural employment share in 2007 \\
$\phi$ & 0.003 & Long-run agricultural employment share \\
$\beta$ & 0.96 & K/Y ratio of 3 (non-agricultural sector) \\
$\sigma_{s}$ & 1.327 & Farm size distribution in 2007 \\
$L_{1900}, L_{2000}$ & 1,1 & Farming land \\
$N_{1900}, N_{2000}$ & $0.27,1$ & Population \\
$v_{1900}, v_{2000}$ & $0.43,1$ & Relative price of investment goods \\
$A_{1900}, A_{2000}$ & $0.36,1$ & Non-agricultural labour productivity \\
$\kappa_{1900}, \kappa_{2000}$ & $0.44,1$ & Agricultural labour productivity \\
$f_{1900}, f_{2000}$ & $0.75,0.02$ & Adoption curve \\
$B_{1900}, B_{2000}$ & $2.2,2.5$ & Adoption curve \\
\hline
\end{tabular}

Note: This table summarizes the calibration. For time series parameters, I display the values at the starting period and the ending period; the pattern of growth of these parameters are described in the text.

tion curve well. In this section, I show that my model can also match other moments which are important in long-run growth, despite they are not directly targeted in the calibration.

Figure 9 shows that the model generates the same pattern of structural transformation, which can be measured either as sectoral value-added share or employment share, as seen in the data. The left panel of Figure 9 shows that the agricultural value-added share decreases over time, and the model-simulated series replicates the data well, even though the calibration process does not directly target this series. The right panel of Figure 9 shows that my model also matches the agricultural employment share over time reasonably well, even though I only target the agricultural employment share at the beginning and end of this period. The agricultural employment share in the data is a bit higher than in the model during the 1930s and 1940s, probably due to the Great Depression and World War II, which are not in my model. 
Figure 9: Model V.S. Data - Structural Transformation
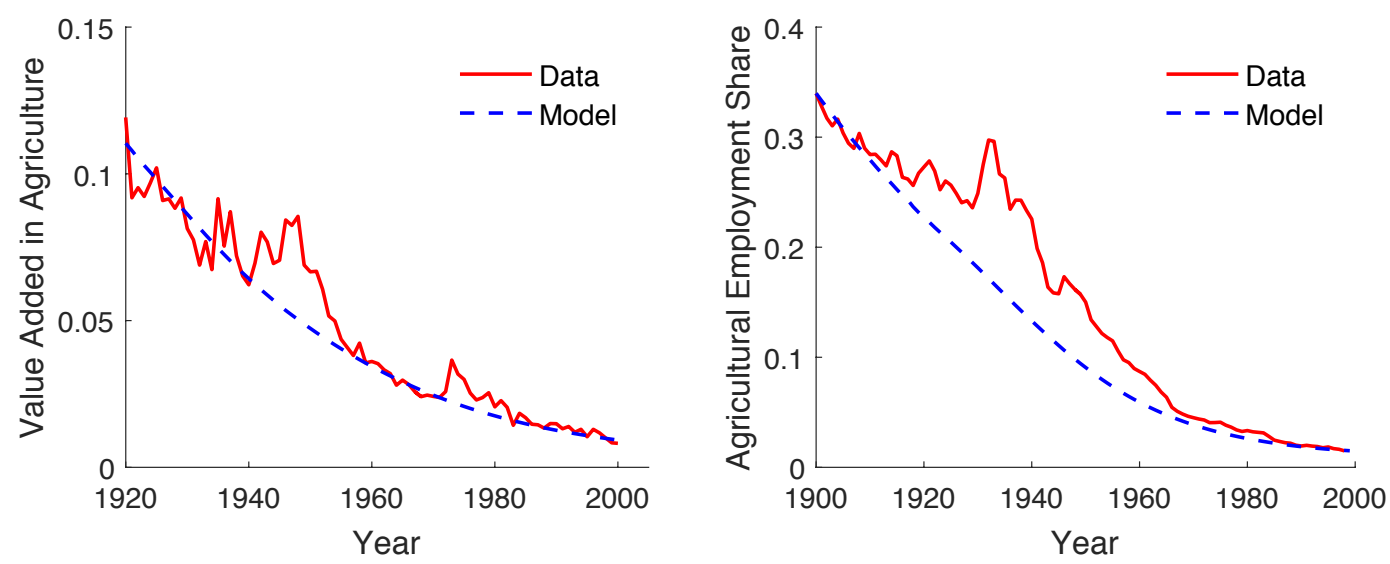

Note: This figure compares the model's prediction on two measures of structural transformation with the data. The left panel shows the agricultural value added share over time; the right panel shows the agricultural employment share over time.

Figure 10: Model V.S. Data - Capital-Output Ratio

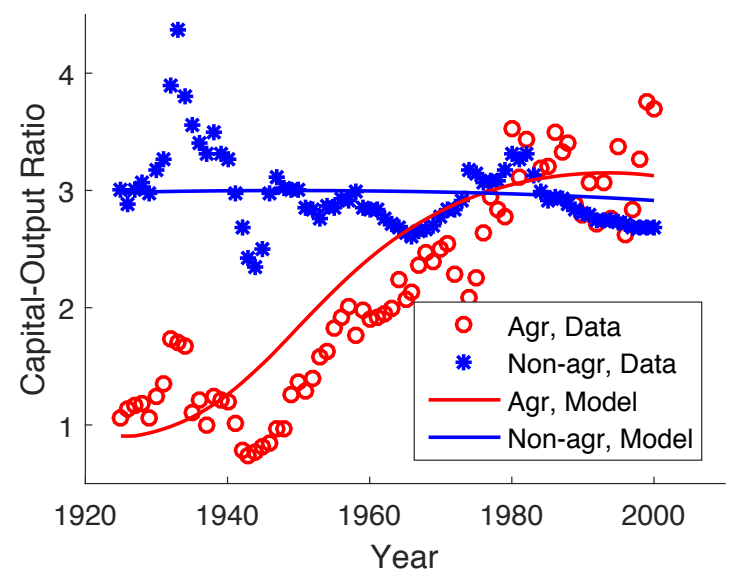


Figure 10 shows that the model is also capable of replicating the sectoral capital-output ratio over time. In particular, the model clearly replicates the capital deepening process in agriculture. Towards the start of the twentieth century, the capital-output ratio in agriculture is much lower than in non-agriculture. This agricultural capital-output ratio starts to increase in the 1940s and catches up to and surpasses the non-agricultural capital-output ratio by the 1980s. Note that I do not explicitly target the capital-output ratio in the agricultural sector; it is the technology adoption channel that accounts for this capital deepening process in agriculture.

My calibration also provides insight into sectoral labour productivity growth of the U.S. economy. Over the twentieth century, labour productivity grows faster in agriculture than in non-agriculture. Recall that the latter only increased 6.9-fold while the former increased 30.4-fold. A portion of this difference in sectoral productivity growth can be accounted for by technology adoption. In fact, this technology adoption channel, together with the capital deepening in agriculture resulting from this technology adoption, accounts for 3.3fold of agricultural labour productivity growth over the twentieth century (i.e., $79.9 \%$ of the difference in sectoral productivity growth). ${ }^{17}$

\section{Quantitative Analysis}

I use the calibrated model to study cross-country differences in agricultural capital intensity and agricultural labour productivity. I focus on the comparison between the United States, which I set as my benchmark, and $20 \%$ of the poorest countries in my sample. ${ }^{18}$

\footnotetext{
${ }^{17}$ Sectoral productivity growth differs by $30.4 / 6.9=4.4$ fold, while technology adoption contributes to 3.3 fold. Therefore, this channel accounts for $\log (3.3) / \log (4.4)=79.9 \%$ of the observed difference in sectoral productivity growth. The remaining portion is explained by the growth of $\kappa$.

${ }^{18}$ The $20 \%$ poorest countries in my sample, sorted by their real GDP per capita, are El Salvador, Malawi, Tanzania, Madagascar, India, Kenya, Egypt, and Pakistan.
} 


\subsection{Aggregate Factors}

This experiment seeks to answer how differences in measured aggregate factors across countries can explain differences in their agricultural capital intensity and labour productivity. After discussing all results, I also use this experiment to illustrate how the technology adoption channel works in my model.

I compare the United States with the poorest $20 \%$ of countries in my sample. Note that cross-country comparable data are only available for years 1980 - 1990. For my cross-country comparison, I take the mean of the 11 years of available data for each country. The first aggregate factor I consider is land endowment $(L)$ : land endowment per capita differs by 2.13-fold between the U.S. and the poor countries. I also consider barrier to investment $(\pi)$ : various literatures have documented that poor countries have higher barriers to investment, leading to distorted prices for capital and lower capital-output ratios (Jones, 1994; Restuccia and Urrutia, 2001). The capital-output ratio, measured in the international price, is 2.08fold higher in the United States compared to the poorest countries in the non-agricultural sector, so I set the barrier $\pi=2.08$ for the poor countries. The third aggregate factor I consider is the economy-wide TFP $(A)$. Labour productivity in the non-agricultural sector is 4.42 -fold higher in the United States versus the poorest countries. I therefore set $A_{\mathrm{US}}$ and $A_{\text {poor }}$ to differ by 2.08 -fold so that the differences in $A$ and $\pi$ jointly contribute to the 4.42-fold difference in non-agricultural labour productivity. Note that I treat all differences in the non-agricultural sector as exogenous and use them to determine the aggregate factor differences. I do not target the agricultural capital-output ratio or labour productivity.

Since my cross-country data are from 1980 - 1990, I perform this experiment based on the parameter values of the year 1985. I vary the parameters $\{L, A, \pi\}$ by $2.13,2.11$, and 2.08 fold respectively as described above, and assume that the economy is in steady state. Using differences in each nations' aggregate factors only, my model can explain a reasonably large 
Table 3: Effects of Aggregate Factors

\begin{tabular}{lccc}
\hline & Data & Model & Explained \\
\hline Agriculture: & & & \\
Capital-output ratio & 3.2 & 2.4 & $75 \%$ \\
$\quad$ Capital-labour ratio & 165.0 & 27.7 & $65 \%$ \\
$\quad$ Labour productivity & 48.8 & 11.4 & $63 \%$ \\
\hline Non-agriculture (targeted): & & & \\
$\quad$ Capital-output ratio & 2.1 & 2.1 & - \\
$\quad$ Labour productivity & 4.4 & 4.4 & - \\
\hline Whole Economy: & & & \\
$\quad$ GDP per capita & 21.4 & 5.1 & $53 \%$ \\
\hline
\end{tabular}

Notes:

[1] All moments are reported as the ratio between the U.S. (the benchmark economy) and the poorest $20 \%$ countries in my sample.

[2] The model's prediction is when the economy-wide TFP, barrier to investment, and land endowment are set to the level of the poorest countries.

[3] Explained portion is the ratio of log model moment over log data moment.

portion of the observed disparity in these nations' agricultural capital intensity and labour productivity. I summarize the results in Table 3. The agricultural capital-output ratio differs by 3.2-fold between the U.S. and the poorest countries, 2.4-fold of which can be explained by the model using differences in aggregate factors. This means that, the aggregate factors explain $\log (2.4) / \log (3.2)=75 \%$ of the observed differences of capital-output ratio in the data. The model also explains 27.7-fold of capital-labour ratio differences and 11.4-fold of agricultural labour productivity differences, which account for $65 \%$ and $63 \%$ of the observed differences in the data. Therefore, using aggregate factor differences only, the model can explain about two-third of the differences in agricultural capital intensity and agricultural labour productivity across countries.

The model also has implications for other moments. With differences in aggregate factors, the agricultural employment share increases to $21.3 \%$, which is considerably higher than the benchmark U.S. economy of this period. Due to smaller land endowement and higher agricultural employment share, the average farm size of poor countries predicted by the 
model is around 30-fold smaller than that of the U.S. This is consistent with Adamopoulos and Restuccia (2014), who find that the average farm size is much smaller in poor countries than in rich countries. The model also predicts a much lower technology adoption rate, decreasing from nearly $100 \%$ in the U.S. to just $26.6 \%$. This is consistent qualitatively with the evidence from the CHAT data set. According to the CHAT dataset, the poor countries in my experiment have on average 1.40 tractors per 1000 hectares, compared to 10.96 tractors per hectare in the U.S., a difference of around 8-fold. ${ }^{19}$ Similarly, agricultural harvesters per 1000 hectares also differ by around 14-fold between the U.S. and the poor countries. Therefore, it is likely that the technology adoption rate of poor countries is only $1 / 8$ to $1 / 14$ of that of the U.S., which is around 10\%. In contrast, recall that using aggregate factor differences, the model predicts the technology adoption rate to be $26.6 \%$ in poor countries. Hence, aggregate factors alone can account for a large portion of the cross-country differences in technology adoption.

If we compare the relative importance of the aggregate factors $\{L, \pi, A\}$, the economywide TFP $(A)$ is the most important factor among these three. Differences in this factor alone can generate 4.9-fold of labour productivity differences in agriculture, roughly $65 \%$ of the 11.4-fold differences when all three factors are considered. The barrier to investment $\pi$ alone can generate 1.8 -fold of labour productivity differences, which accounts for $24 \%$ of the 11.4-fold differences. The land endowment differences are, however, relatively unimportant. It only generates 1.2 -fold differences, or $7 \%$ of the 11.4 -fold differences. ${ }^{20}$ This is consistent with Adamopoulos and Restuccia (2014), who also find differences in land endowment to be relatively unimportant.

\footnotetext{
${ }^{19}$ I calculate a tractor-to-land ratio instead of a tractor-to-farmer ratio. This is because farmers with tractors usually operate larger farms, so the tractor-to-farmer ratio would understate the technology adoption rate in its early stages. For example, there is more than a 360-fold difference in the tractor-to-farmer ratio between the U.S. and poor countries, which is considerably larger than if we use the tractor-to-land ratio.

${ }^{20}$ The remaining 1.1-fold is contributed by interactions among these three factors.
} 
Table 4: Importance of Technology Adoption

\begin{tabular}{lccc}
\hline & Data & Model & No adoption \\
\hline Agriculture: & & & \\
$\quad$ Capital-output ratio & 3.2 & 2.4 & 0.8 \\
$\quad$ Capital-labour ratio & 165.0 & 27.7 & 6.4 \\
$\quad$ Labour productivity & 48.8 & 11.4 & 7.9 \\
\hline Non-agriculture (targeted): & & & \\
$\quad$ Capital-output ratio & 2.1 & 2.1 & 2.1 \\
$\quad$ Labour productivity & 4.4 & 4.4 & 4.4 \\
\hline Whole Economy: & & & \\
$\quad$ GDP per capita & 21.4 & 5.1 & 4.7 \\
\hline
\end{tabular}

Notes:

[1] All moments are reported as the ratio between the U.S. (the benchmark economy) and the poorest $20 \%$ countries in my sample.

[2] The model's prediction is when the economy-wide TFP, barrier to investment, and land endowment are set to the level of the poorest countries.

[3] Explained portion is the ratio of log model moment over log data moment.

\subsection{The Channel of Technology Adoption}

The novelty of my model, compared to the existing literature on agricultural productivity, is the technology adoption channel. In this section, I use the previous experiment to illustrate how this channel of technology adoption works, and why it amplifies agricultural productivity differences across countries.

Recall the previous experiment quantifying the explanatory power of aggregate factors for international differences in agricultural capital intensity and labour productivity. I now perform this experiment again without technology adoption channel: the only available technology is the modern technology. I choose to keep modern technology instead of the traditional one to make results comparable to the literature: papers in this literature often calibrate agricultural technology to the current U.S. data, resulting in an agricultural technology similar to the modern technology in my model. Table 4 compares the predictions of my model with and without technology adoption. When we shut down the channel of technology adoption, the model predicts that poor countries will have higher agricultural 
capital-output ratio than the U.S., which is opposite in direction compared to data. Intuitively, poor countries have lower agricultural productivity, with inelastic demand of the agricultural good near the subsistence level of consumption. Hence, the price of the agricultural good is much more expensive in poor countries, and as a result, farmers can afford to use more capital in production. That is why the real capital-output ratio is higher in poor countries than in the U.S. Note that the nominal capital-output ratio, which equals $\alpha_{m} / r$ without technology adoption, is constant across countries. Therefore, technology adoption is the key channel for matching the stylized fact that the cross-country differences in capital intensity are larger in agriculture than in the non-agricultural sector.

Without the technology adoption channel, the model's predictions would also suffer in other moments. For example, recall the previous experiment quantifying the explanatory power of aggregate factor differences. With technology adoption, my model generates a 27.7fold difference in agricultural capital-labour ratio. In contrast, the model without technology adoption would only generate a 6.4-fold difference. Similarly, the predicted agricultural productivity differences also reduce from 11.4-fold to 7.9-fold. This implies that a model without technology adoption would substantially understate the explanatory power of aggregate factors. In other words, the technology adoption channel amplifies the importance of aggregate factors in explaining the international differences in agricultural capital intensity and labour productivity.

The channel of technology adoption amplifies agricultural productivity differences in two ways. First, different levels of technology adoption imply different levels of agricultural capital intensity, and in turn, different labour productivity. Second and more important, technology adoption directly affects the sectoral TFP of agriculture. This is because modern technology is more productive than traditional technology ( $B>1$ in the calibration), and the factor shares and span of controls also change with technology adoption. To see this, 
consider the following equation

$$
\frac{Y_{a}}{N_{a}}=A_{a}^{\frac{1}{1-\alpha-\gamma}}\left(\frac{K_{a}}{Y_{a}}\right)^{\frac{\alpha}{1-\alpha-\gamma}}\left(\frac{L}{Y_{a}}\right)^{\frac{\gamma}{1-\alpha-\gamma}}
$$

which decomposes agricultural labour productivity into contributions from endogenous sectoral TFP $\left(A_{a}\right)$, capital-output ratio $\left(\frac{K_{a}}{Y_{a}}\right)$, and land-output ratio $\left(\frac{L_{a}}{Y_{a}}\right)$. We can again look at the comparison of the model's predictions with and without technology adoption in Table 4. The model's prediction differs by 1.56 -fold on labour productivity $\left(\frac{Y_{a}}{N_{a}}\right), 1.23$-fold on capitaloutput ratio raised by the capital share $\left(\left(\frac{K_{a}}{Y_{a}}\right)^{\frac{\alpha}{1-\alpha-\gamma}}\right)$, and virtually none in land-output ratio. Therefore, changes in endogenous sectoral TFP contributes to the remaining 1.27-fold difference $(1.56 / 1.23=1.27)$. Note that changes in sectoral TFP are completely from technology adoption choice, since the exogenous productivity parameters $A$ and $\kappa$ are the same in this comparison. To summarize our findings from this exercise, technology adoption amplifies labour productivity differences by 1.56 folds given the aggregate factor differences, where $46.4 \%(=\log (1.23) / \log (1.56))$ is from capital deepening, and the remaining $53.6 \%$ is from changes in sectoral TFP.

It is also illustrative to reconsider the comparison between the U.S. and poor countries. The differences in the economy-wide TFP $\left(A_{\mathrm{US}}\right.$ V.S. $\left.A_{\text {Poor }}\right)$ plays three roles in agriculture. First, it directly affects agricultural productivity as an exogenous part of agricultural sectoral TFP; second, it affects agricultural capital intensity through technology adoption; and third, it affects the endogenous part of the sectoral TFP through technology adoption. In the nonagricultural sector, however, only the direct effect is present. This is how my model is able to generate larger labour productivity differences in agriculture than in the non-agricultural sector across countries.

This comparison also suggests that standard development accounting exercise will underestimate the importance of economy-wide TFP in quantifying agricultural labour productivity differences across countries. The key assumption of development accounting is that the 
capital-output ratio is exogenous, independent of the economy-wide TFP $(A)$, which is true in the standard neoclassical growth model (Hall and Jones, 1999). In my model, however, the economy-wide TFP affects technology adoption, which in turn has an impact on capitaloutput ratio. As a result, some variation of capital-output ratio should also be contributed to the variation of economy-wide TFP differences across countries. For example, my experiment shows that the 1.23-fold productivity difference contributed by capital-output ratio between the U.S. and the poor countries is due to technology adoption, which is mainly a result of the economy-wide TFP differences.

It is important to emphasize that so far the quantitative analysis is based on a neoclassical framework with few frictions: I assume the U.S. and the poorest countries only differ in the measured aggregate factor differences, and they account for a large portion of differences in observed agricultural capital intensity and labour productivity. In particular, technology adoption differs across countries mainly due to the price effect: it is not profitable for farmers in poor countries to adopt the modern technology and use capital to substitute labour, because the price of labour is cheap enough while modern technology is labour-saving. This result is consistent with experiences on tractor promotion projects in many Sub-Saharan countries. Between 1970-1980, local governments and non-governmental organizations provided tractors to farmers either through subsidized credit or state sponsored tractor rentals. However, most of these projects failed as "in many tractor project areas no tractors can be found today (Pingali, 2007)", mostly because human labour is cheap enough in these areas so the demand of machinery is low (Pingali et al., 1987). This evidence indicates that capital frictions, in particular the collateral constraint of acquiring machinery, are not likely to play a large role. This is also confirmed in the empirical development literature which finds that relaxing credit constraint for farmers do not necessarily lead to more investment (Kaboski and Townsend, 2012; Karlan et al., 2014). Therefore, instead of capital frictions, I examine the role of land misallocation, which is shown as important by recent literature, to 
see whether they are able to account for the unexplained differences by aggregate factors.

\subsection{Land Misallocation}

This experiment examines the role of land misallocation. Recent literature shows that resource misallocation negatively affects aggregate productivity. In particular, land misallocation is identified as one of the main obstacles in agricultural development, since it is prevalent in low-income countries where land property rights are usually poorly defined. For example, Adamopoulos and Restuccia (2014) show that the distribution of farm size differs substantially across countries, which largely arises from policies and institutions that misallocate land across farmers. They further show that these differences in farm size distribution have important implications on cross-country agricultural productivity differences. Chen (2016) focuses on untitled land as a specific form of land misallocation. In many poor countries, farmers do not have legal ownership of land, which is officially owned by the state or government. Local leaders grant this untitled land to farmers in an egalitarian way and farmers are unable to trade or rent their allocated land amongst each other. Chen (2016) finds that while untitled land is prevalent in poor countries, it is almost non-exist in rich countries. In this experiment, I use my model to study how untitled land can affect agricultural capital intensity and agricultural productivity.

I model untitled land together with aggregate factors described before. In particular, I assume every farmer is allocated an endowment of land, though this land cannot be traded or rented due to lack of legal ownership. This allocation is usually on an egalitarian or nepotistic basis, and is generally uncorrelated with farmer ability (Goldstein and Udry, 2008; Restuccia and Santaeulalia-Llopis, 2015). For simplicity, I therefore assume that every farmer is allocated the same amount of land, which means that the farm size distribution is degenerate. $^{21}$

\footnotetext{
${ }^{21}$ Chen (2016) shows that assuming a uniform allocation of land yields similar quantitative results com-
} 
Table 5: Importance of Untitled Land

\begin{tabular}{lcccc}
\hline & Data & \multicolumn{2}{c}{ Model } & Explained \\
& & AF Only & w/ Unt. Land & \\
\hline Agriculture: & & & & \\
Capital-output ratio & 3.2 & 2.4 & 4.3 & $125 \%$ \\
Capital-labour ratio & 165.0 & 27.7 & 71.5 & $84 \%$ \\
Labour productivity & 48.8 & 11.4 & 16.6 & $72 \%$ \\
\hline
\end{tabular}

Notes:

[1] All moments are reported as the ratio between the U.S. (the benchmark economy) and the poorest $20 \%$ countries in my sample.

[2] The "AF Only" column shows the model's prediction when only aggregate factors are considered, while the next column shows the prediction after adding untitled land to the model.

[3] Explained portion is the ratio of log model moment over log data moment.

Table 5 shows the results of the enriched model with untitled land. We can see that the predictions of the enriched model match the data better. For example, the model is now able to generate a 4.3-fold difference in capital-output ratio and a 71.5 -fold difference in capital-labour ratio between the U.S. and the poorest countries, which are much closer to the data. Untitled land further lowers the agricultural productivity by around 45\%: the model with untitled land predicts a 16.6-fold difference in labour productivity, compared to the original 11.4-fold prediction without untitled land.

Untitled land affects agricultural productivity in two ways. First, as untitled land cannot be traded/rented across farmers, there is land misallocation across farmers, which directly lowers agricultural productivity. Second, untitled land impedes technology adoption. The adoption rate of the modern technology decreases to less than $1 \%$, compared to $26.6 \%$ without untitled land. Intuitively, modern technology is profitable only when the farm size is large enough to afford the fixed cost of technology adoption. With untitled land, however, the egalitarian allocation of land prevents higher-ability farmers from renting or buying land pared to assuming an idiosyncratic allocation of land, provided that the farm size distribution is uncorrelated with ability. 
and operating larger farms. As a result, farmers have little incentive to pay the fixed cost of adopting modern technology. Untitled land is typically thought of as a friction in the land market. However, it affects capital intensity indirectly through its impact on technology adoption. Therefore, in my framework, untitled land creates joint misallocation in land and capital markets.

Note that other forms of land market frictions can affect technology adoption in a similar fashiond. For example, imposing ceilings on farm size is another common form of land market friction Adamopoulos and Restuccia (2015) describe a land reform in the Philippines, imposing a ceiling on farm size (5 hectares) and restricting farm land transaction. Similar to untitled land, land ceilings also prevent higher-ability farmers from operating larger farms and therefore impede technology adoption. The key similarity of these land frictions is that they prevent farms from expanding, while technology adoption depends crucially on the profitability of modern technology on large farms.

\subsection{Long-Run Growth}

Previous experiments study cross-country differences and show that aggregate factors and untitled land impede technology adoption in poor countries and therefore affect their current agricultural productivity. This section studies the pattern of long-run growth and convergence. In particular, I consider the following experiment: suppose we assume that productivity and endowments grow at the same rates as observed in the twentieth century. When will technology adoption happen in poor countries with untitled land? How will agricultural productivity evolve over time in poor countries relative to the U.S.?

I assume that for the period 2000-2050, time series parameters, including economy-wide TFP $\left(A_{t}\right)$, agricultural-specific productivity $\left(\kappa_{t}\right)$, investment-specific productivity $\left(v_{t}\right)$, and population $\left(N_{t}\right)$, grow at the same rates as observed for the period 1900-2000. These growth 
rates are the same for both the U.S. and the poor countries. Furthermore, I assume that aggregate factor differences between the U.S. and poor countries remain time-invariant at the same levels as in Section 5.1: $L_{\mathrm{US}}=2.13 L_{\mathrm{Poor}}, A_{\mathrm{US}}=2.11 A_{\mathrm{Poor}}$, and $\pi_{\mathrm{Poor}}=2.08 \pi_{\mathrm{US}}$. Untitled land is also equally distributed among farmers as in Section 5.3. I then change the level of $f_{t}$ and $\kappa_{t}$ for poor countries, such that their technology adoption rate is $10 \%$ and agricultural labour productivity is $1 / 48$ of that of the U.S. for the year 2000. Recall that $\kappa_{t}$ is a residual parameter capturing factors that affect agricultural productivity but are not explicitly modelled, and $f_{t}$ captures the cost of technology adoption in reduced form. Therefore, by varying these two parameters, the model perfectly matches the data of agricultural productivity and technology adoption for poor countries. This implicitly requires that these two parameters capture all factors that are not explicitly modelled. Note that the level of $\kappa_{t}$ and $f_{t}$ differ between the U.S. and poor countries by 2.13- and 2.87-fold, while the growth rates are the same. I also assume that $f_{t}$ and $B_{t}$ are time-invariant after 2000. This assumption is due to the fact that technology adoption is largely completed in the U.S. and other rich countries by the year 2000. Therefore, it would not be profitable for research and development firms in rich countries to further improve the modern technology.

I then let the economies of both the U.S. and poor countries grow for 50 years. Figure 11 shows the long-run growth pattern of both the U.S. and poor countries, with and without untitled land. Let us first focus on the comparison between the U.S. (black solid curve) and poor countries with untitled land (red dashed line). The top panel shows that poor countries with untitled land start technology adoption roughly 70 years later than the U.S. This adoption lag translates to lower agricultural labour productivity, shown in the middle and bottom panels. Before modern technology was adopted in the U.S., the US-poor agricultural productivity differences were below 20-fold. When technology adoption commenced in the U.S., US-poor agricultural productivity differences also increased. These differences peak when technology adoption is completed in the U.S. but barely initiated in poor countries. As 
Figure 11: Long-Run Growth and Convergence
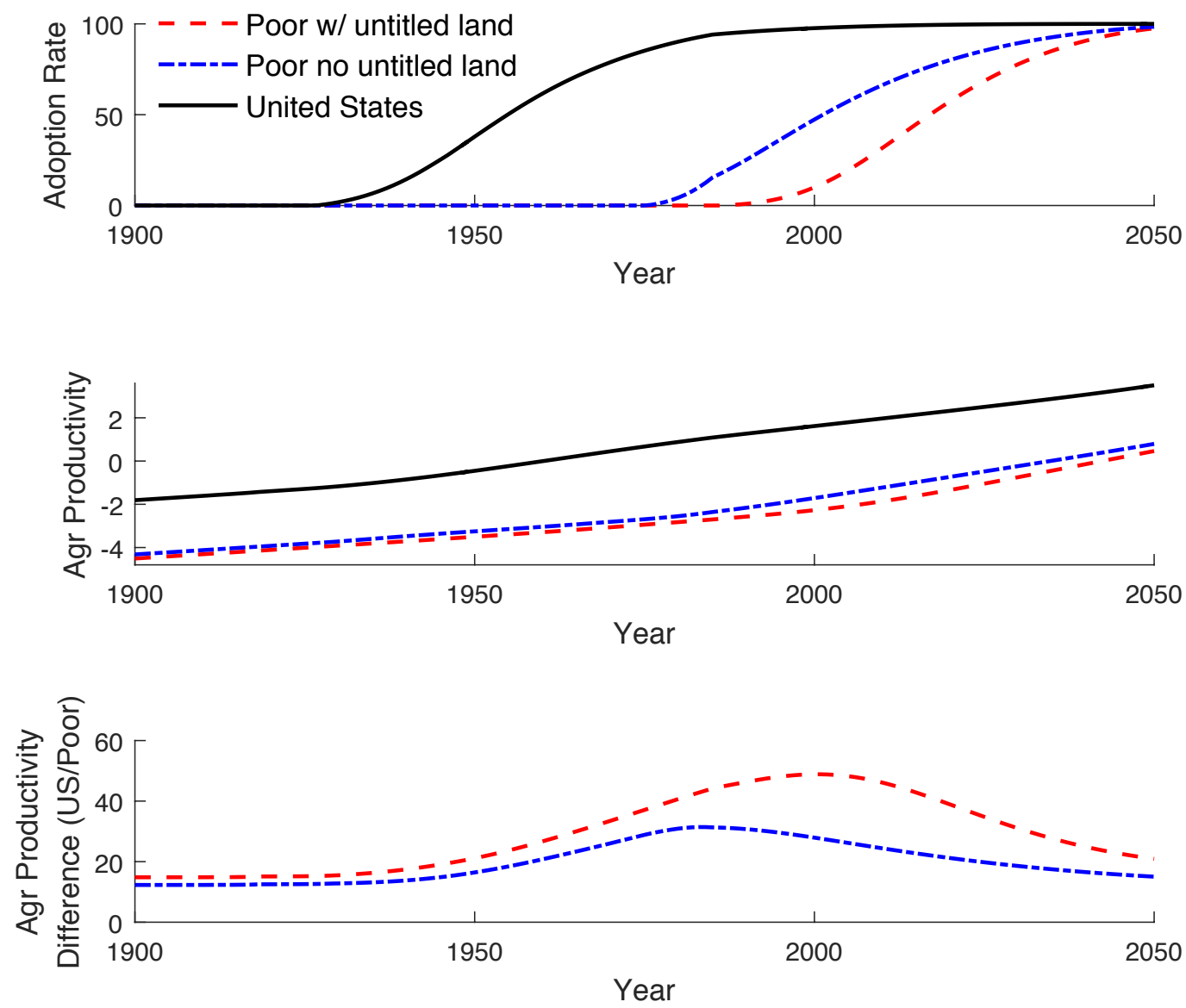

Note:

[1] The black solid curve represents moments in the U.S., while the red and blue dashed curves represent moments in poor countries with and without untitled land, respectively.

[2] The top panel shows the rate of modern technology adoption, defined as the percentage of output produced by farms with modern technology. The middle panel shows agricultural labour productivity. The bottom panel shows differences in agricultural labour productivity between the U.S. and the poor countries, measured as $\frac{Y_{a} /\left.N_{a}\right|_{\text {US }}}{Y_{a} /\left.N_{a}\right|_{\text {Poor }}}$. 
poor countries adopt more modern technology, the differences gradually diminish. Therefore, there is a period, with length equal to the poor countries' technology adoption lag, in which US-poor agricultural productivity differences are temporarily larger due to differences in technology adoption. Note that agricultural productivity in poor countries will never the same to that of the U.S., as illustrated in the middle and bottom panels, due to aggregate factor differences and existence of untitled land.

Land titling also has long-run impacts. If there were no untitled land in poor countries (i.e. farmers could sell or rent their land frictionlessly), then the technology adoption lag would be substantially shortened to around 50 years. Furthermore, the agricultural productivity differences at the peak would also reduce from around 50-fold to around 30-fold. Comparing poor countries with untitled land (red dashed curve) to hypothetical poor countries without untitled land (blue dashed curve) in the bottom panel, we can see that untitled land has two impacts. First, it introduces static land misallocation, reflected by the distance between the two curves before technology adoption starts and after it finishes. Second, the existence of untitled land impedes technology adoption, reflected by the much wider gap between the two curves around the year 2000 .

\section{Conclusion}

The differences of capital intensity between rich and poor countries are larger in agriculture than in non-agriculture. Meanwhile, the capital intensity of the U.S. agricultural sector increases in the 20th century. I study these phenomena using a model featuring technology adoption in agriculture, which can account for the increasing agricultural capital intensity in the U.S. Then, I use this model to perform cross-country analysis and find that countries'

aggregate factors can explain around two thirds of rich-poor differences in capital intensity and labour productivity, and show that accounting for technology adoption choice is crucial 
for the model to match the data. I further show that untitled land, which is prevalent in poor countries, also impedes technology adoption and reduce labour productivity in agriculture.

These findings suggest that a detailed study linking land misallocation and technology adoption in agriculture is important. This is a topic on which I provide some suggestive evidence, but otherwise leave open for future research. In particular, there are rich micro data on agricultural production for several different developing countries. These data can be used to empirically identify the causal relationship between land misallocation and agricultural technology adoption by exploiting exogenous variations in local land market institutions within a country. This relationship is also relevant for policy analysis, since land misallocation usually arises from policy distortions.

My paper also suggests that capital deepening is crucial in determining sectoral labour productivity growth over time. This topic is related to the structural transformation literature, which typically finds that labour productivity grows faster in the goods sector than in the service sector, resulting in resources being reallocated to the service sector. Capital deepening at the sectoral level, for both the goods sector and the service sector, is therefore a potential channel to explain this difference in labour productivity growth between the goods and service sectors. I focus on the agricultural sector only in this paper, while leave the comparison between the goods sector and the service sector for future research. 


\section{References}

Adamopoulos, T. (2011). Transportation costs, agricultural productivity, and cross-country income differences. International Economic Review, 52(2):489-521.

Adamopoulos, T., Brandt, L., Leight, J., and Restuccia, D. (2016). Misallocation, selection and productivity: A quantitative analysis with panel data from china. Working Paper.

Adamopoulos, T. and Restuccia, D. (2014). The size distribution of farms and international productivity differences. American Economic Review, 104(6):1667-1697.

Adamopoulos, T. and Restuccia, D. (2015). Land reform and productivity: A quantitative analysis with micro data. University of Toronto Working Paper.

Alvarez-Cuadrado, F., Long, N. V., and Poschke, M. (2015). Capital-labor substitution, structural change and growth. Working Paper.

Ayerst, S. (2016). Idiosyncratic distortions and technology adoption. Working Paper.

Caselli, F. (2005). Accounting for cross-country income differences. Handbook of Economic Growth, 1:679 - 741 .

Caunedo, J. and Keller, E. (2016). Capital obsolescence and agricultural productivity. Working Paper.

Chen, C. (2016). Untitled land, occupational choice, and agricultural productivity. Working Paper.

Comin, D. and Hobijn, B. (2004). Cross-country technology adoption: making the theories face the facts. Journal of Monetary Economics, 51(1):39 - 83.

Comin, D. and Hobijn, B. (2010). An exploration of technology diffusion. American Economic Review, 100(5):2031-59.

Donovan, K. (2014). Agricultural risk, intermediate inputs, and cross-country productivity differences. University of Notre Dame Working Paper.

Feenstra, R. C., Inklaar, R., and Timmer, M. P. (2015). The next generation of the penn world table. American Economic Review, 105(10):3150-82.

Goldstein, M. and Udry, C. (2008). The profits of power: Land rights and agricultural investment in ghana. Journal of Political Economy, 116(6):981-1022.

Gollin, D. (2002). Getting income shares right. Journal of Political Economy, 110(2):458474.

Gollin, D., Lagakos, D., and Waugh, M. E. (2014a). Agricultural productivity differences across countries. American Economic Review: Papers and Preceedings, 104(5):165-170.

Gollin, D., Lagakos, D., and Waugh, M. E. (2014b). The agricultural productivity gap. Quarterly Journal of Economics, 129(2):939-993. 
Gollin, D., Parente, S. L., and Rogerson, R. (2002). The role of agriculture in development. American Economic Review: Papers and Proceedings, 92(2):160-164.

Gollin, D., Parente, S. L., and Rogerson, R. (2004). Farm work, home work and international productivity differences. Review of Economic Dynamics, 7(4):827-850.

Gollin, D., Parente, S. L., and Rogerson, R. (2007). The food problem and the evolution of international income levels. Journal of Monetary Economics, 54(4):1230-1255.

Gollin, D. and Rogerson, R. (2014). Productivity, transport costs and subsistence agriculture. Journal of Development Economics, 107:38-48.

Gort, M., Greenwood, J., and Rupert, P. (1999). Measuring the rate of technological progress in structures. Review of Economic Dynamics, 2(1):207-230.

Gottlieb, C. and Grobovšek, J. (2015). Communal land and agricultural productivity. Working Paper.

Greenwood, J., Hercowitz, Z., and Krusell, P. (1997). Long-run implications of investmentspecific technological change. American Economic Review, 87(3):342-362.

Hall, R. E. and Jones, C. I. (1999). Why do some countries produce so much more output per worker than others? The Quarterly Journal of Economics, 114(1):pp. 83-116.

Hansen, G. D. and Prescott, E. C. (2002). Malthus to solow. American Economic Review, 92(4):1205-1217.

Hayami, Y. and Ruttan, V. W. (1985). Agricultural Development: An International Perspective. The Johns Hopkins Press.

Helpman, E., Melitz, M. J., and Yeaple, S. R. (2004). Export versus FDI with heterogeneous firms. The American Economic Review, 94(1):300-316.

Herrendorf, B., Rogerson, R., and Ákos Valentinyi (2014). Growth and structural transformation. Handbook of Economic Growth, 2:855-941.

Herrendorf, B. and Schoellman, T. (2015). Why is measured productivity so low in agriculture? Review of Economic Dynamics, 18(4):1003 - 1022.

Hsieh, C.-T. and Klenow, P. J. (2007). Relative prices and relative prosperity. American Economic Review, 97(3):562-585.

Hsieh, C.-T. and Klenow, P. J. (2009). Misallocation and manufacturing TFP in China and India. Quarterly Journal of Economics, 124(4):1403-1448.

Jones, C. I. (1994). Economic growth and the relative price of capital. Journal of Monetary Economics, 34(3):359 - 382 .

Kaboski, J. P. and Townsend, R. M. (2012). The impact of credit on village economies. American Economic Journal: Applied Economics, 4(2):98-133. 
Karlan, D., Osei, R., Osei-Akoto, I., and Udry, C. (2014). Agricultural decisions after relaxing credit and risk constraints. The Quarterly Journal of Economics, 129(2):597-652.

Kongsamut, P., Rebelo, S., and Xie, D. (2001). Beyond balanced growth. Review of Economic Studies, 68(4):869-882.

Lagakos, D. and Waugh, M. E. (2013). Selection, agriculture, and cross-country productivity differences. American Economic Review, 103(2):948-980.

Larson, D. F., Butzer, R., Mundlak, Y., and Crego, A. (2000). A cross-country database for sector investment and capital. World Bank Economic Review, 14(2):371-391.

Manuelli, R. E. and Seshadri, A. (2014). Frictionless technology diffusion: The case of tractors. American Economic Review, 104(4):1368-1391.

Ngai, L. R. (2004). Barriers and the transition to modern growth. Journal of Monetary Economics, 51(7):1353-1383.

Parente, S. L. and Prescott, E. C. (1994). Barriers to technology adoption and development. Journal of Political Economy, 102(2):298-321.

Pingali, P. (2007). Agricultural mechanization: Adoption patterns and economic impact. Handbook of Agricultural Economics, 3:2779-2805.

Pingali, P., Bigot, Y., and Binswanger, H. P. (1987). Agricultural Mechanization and the Evolution of Farming Systems in Sub-Saharan Africa. Published for the World Bank, The Johns Hopkins University Press.

Restuccia, D. (2004). Barriers to capital accumulation and aggregate total factor productivity. International Economic Review, 45(1):225-238.

Restuccia, D. and Rogerson, R. (2008). Policy distortions and aggregate productivity with heterogeneous establishments. Review of Economic Dynamics, 11(4):707-720.

Restuccia, D. and Santaeulalia-Llopis, R. (2015). Land misallocation and productivity. University of Toronto Working Paper.

Restuccia, D. and Urrutia, C. (2001). Relative prices and investment rates. Journal of Monetary Economics, 47(1):93 - 121.

Restuccia, D., Yang, D. T., and Zhu, X. (2008). Agriculture and aggregate productivity: A quantitative cross-country analysis. Journal of Monetary Economics, 55(2):234-250.

Sunding, D. and Zilberman, D. (2001). The agricultural innovation process: Research and technology adoption in a changing agricultural sector. Handbook of Agricultural Economics, 1(A):207-261.

Timmer, M. P., Dietzenbacher, E., Los, B., Stehrer, R., and de Vries, G. J. (2015). An illustrated user guide to the world inputoutput database: the case of global automotive production. Review of International Economics, 23(3):575-605. 
Tombe, T. (2015). The missing food problem. American Economic Journal: Macroeconomics, $7(3): 226-58$.

Valentinyi, A. and Herrendorf, B. (2008). Measuring factor income shares at the sectoral level. Review of Economic Dynamics, 11(4):820-835.

Yang, D. T. and Zhu, X. (2013). Modernization of agriculture and long-term growth. Journal of Monetary Economics, 60(3):367-382. 